\title{
Six-minute walk test in non-insulin-dependent diabetes mellitus patients living in Northwest Africa
}

This article was published in the following Dove Press journal:

Diabetes, Metabolic Syndrome and Obesity:Targets and Therapy

6 August 2012

Number of times this article has been viewed

\author{
Imed Latiri' \\ Rihab Elbey' \\ Kamel Hcini' \\ Afif Zaoui ${ }^{2}$ \\ Bessam Charfeddine ${ }^{3}$ \\ Mohamed Ridha Maarouf ${ }^{4}$ \\ Zouhair Tabka ${ }^{1,5}$ \\ Abdelkrim Zbidi ${ }^{1,5}$ \\ Helmi Ben Saad ${ }^{1,5}$ \\ 'Laboratory of Physiology, University \\ of Sousse, ${ }^{2}$ Department of Physical \\ Medicine. Sahloul Hospital, \\ ${ }^{3}$ Laboratory of Biochemistry, Basic \\ Health Group, ${ }^{4}$ Basic Health Group, \\ ${ }^{5}$ Department of Physiology and \\ Functional Exploration, Farhat Hached \\ Hospital, Sousse, Tunisia
}

Correspondence: Helmi Ben Saad Laboratory of Physiology, Faculty of Medicine of Sousse, Mohamed Karoui Street, Sousse 4000, Tunisia

Tel +21698697024

Fax +21673224899

Email helmi.bensaad@rns.tn
Introduction: International recommendations of the exploration of non-insulin-dependent diabetes mellitus (NIDDM) are focused on deficiency and not incapacity.

Aims: (1) To estimate the incapacity of NIDDM patients through the 6-minute walk test (6MWT) data. (2) To determine their 6-minute walk distance (6MWD) influencing factors (3) To compare data of NIDDM patient group (PG; $n=100)$ with those of two control groups (CG): CG1 ( $\mathrm{n}=174$, healthy nonobese and nonsmoker); CG2 $(\mathrm{n}=55$, obese nondiabetic free from comorbidities).

Population and methods: The anthropometric, socioeconomic, clinical, metabolic, and 6MWT data of 100 NIDDM patients (45 females) were collected.

Results: Total sample means \pm standard deviation of age, weight, and height were $54 \pm 8$ years, $81 \pm 14 \mathrm{~kg}$, and $1.64 \pm 0.09 \mathrm{~m}$. (1) Measured 6MWD (566 $\pm 81 \mathrm{~m}$ ) was significantly lower than the theoretical $6 \mathrm{MWD}(90 \% \pm 12 \%)$. The profile of the PG carrying the $6 \mathrm{MWT}$, was as follows: $23 \%$ had an abnormal $6 \mathrm{MWD}$; at the end of the $6 \mathrm{MWT}, 21 \%$ and $12 \%$ had, respectively, a low heart rate and a high dyspnea $(>5 / 10)$, and $4 \%$ had desaturation during the walk. The estimated "cardiorespiratory and muscular chain" age (68 \pm 16 years) was significantly higher than the chronological age. (2) The factors that significantly influenced the 6MWD $\left(r^{2}=0.58\right)$ are included in the following equation: $6 \mathrm{MWD}(\mathrm{m})=-73.94 \times$ gender $(0$, male; 1 , female $)-3.25 \times$ age (years $)+7.33 \times$ leisure activity score $-35.57 \times$ obesity $(0$, no; 1 , yes $)+32.86 \times$ socioeconomic level $(0$, low; 1 , high $)-27.67 \times$ cigarette use $(0$, no; 1 , yes $)+8.89 \times$ resting oxyhemoglobin saturation -105.48 . (3) Compared to the CGs, the PG had a significantly $(P<0.05)$ lower 6MWD $(100 \%+9 \%$ and $100 \%+8 \%$, respectively, for the CG1 and CG2).

Conclusion: NIDDM seems to accelerate the decline of the submaximal aerobic capacity evaluated through the 6MWD.

Keywords: 6-minute walk test, non-insulin-dependent diabetes mellitus, physical activity, functional incapacity

\section{Introduction}

The Maghreb (region of Northwest Africa comprising five countries: Tunisia, Morocco, Algeria, Libya, and Mauritania) is undergoing an epidemiological transition characterized by a decrease of infectious diseases and an increase in chronic noninfectious ones. ${ }^{1}$ This increase is largely due to a marked change in lifestyle (sedentary lifestyle, obesity, and stress of urbanization and labor), including changes in food consumption patterns. ${ }^{1}$ Among noninfectious chronic diseases, non-insulin-dependent diabetes mellitus (NIDDM), a disease marked by expansion over the past decade, is becoming a real public health emergency. ${ }^{2}$ For example, its prevalence in North Africa is estimated at $10 \%{ }^{3}$ NIDDM poses a major public health problem, more particularly with 
the cardiovascular complications it causes (myocardial infarction [MI], occlusion of arteries of lower limbs, stroke). ${ }^{1,3}$

To better explore this killer disease, it would be interesting to refer to the World Health Organization's latest classification of the natural history of chronic diseases, reporting three evolutionary stages: ${ }^{4}$ deficiency, incapacity, and social disadvantage. The evaluation of incapacity (clinically characterized by dyspnea, pain in the lower limbs, and intermittent claudication ${ }^{3,5}$ ) is considered essential, because alone it can predict the future functioning of the patient. ${ }^{6}$ This is the determination of exercise tolerance through, for example, data from a field test such as the 6-minute walk test (6MWT), which explores the cardiorespiratory and muscle chain. ${ }^{6}$ The social disadvantage is the psychosocial impact of the disease. This is the assessment of the quality of life (QOL).

Internationally, several recommendations for NIDDM management have been developed by scientific societies. ${ }^{5,7-11}$ These recommendations mainly focus on the exploration of deficiency (blood tests [glucose, glycated hemoglobin $\left\{\mathrm{HbA}_{1 \mathrm{c}}\right\}$, lipid profile, microalbuminuria, renal function], blood pressure). These explorations are conducted for static diagnostic purposes or to detect degenerative complications. However, none of these societies recommend the exploration of incapacity, ${ }^{5,7-11}$ while two recent studies $^{12,13}$ have shown that NIDDM significantly alters submaximal aerobic capacity. These two studies unfortunately have methodological shortcomings: inclusion of patients with NIDDM and heart failure ${ }^{13}$ or inclusion of only very elderly patients. ${ }^{12}$

The assessment of functional incapacity, for example, through 6MWT data (endurance test, intensity moderately higher than daily living activities ${ }^{6,14}$ ), is desirable. Indeed, the skill of walking is a reflection of the ability to maintain a number of daily-life activities for patients. ${ }^{6}$ Therefore, it is an important QOL component. ${ }^{6}$

Hence the aims of our study, done in NIDDM patients living in Northwest Africa, are:

1. To estimate the incapacity of NIDDM patients by establishing their profile during the 6MWT: number of patients having an abnormal 6MWD, and/or stopping while walking, and/or having desaturation, and/or expressing dyspnea at the end of the test, and/or showing impaired chronotropic response.

2. To determine factors influencing their 6MWD and to compare their chronological and estimated "cardiorespiratory and muscular chain" ages.
3. To compare data of NIDDM patient group (PG; $\mathrm{n}=100)$ with those of three control groups (CGs): CG1 $(n=174)$, healthy nonobese and nonsmoker; CG2 $(\mathrm{n}=55)$, nondiabetic obese, free from comorbidities; CG3 ( $=59)$, nondiabetic "all comers."

\section{Population and methods Study design}

We performed this cross-sectional study over a 5-month period in Farhat HACHED Hospital's Physiology and Functional Exploration Department and in the Basic Health Group's Laboratory of Biochemistry in Sousse (altitude $<100 \mathrm{~m}$ ), Tunisia.

Approval for the study was obtained from the hospital's ethics committee, and written consent was obtained from all study participants.

NIDDM patients were recruited in three ways. We contacted general practitioners and/or endocrinology specialists. An article was published in a weekly newspaper announcing the need for recruitment of NIDDM patients. Informational letters clarifying the aims of the study were then put up at the hospital and the local medical school.

\section{NIDDM patient group}

Only patients aged over 40 years with an NIDDM status for more than 5 years were included. Noninclusion criteria were as follows: type 1 diabetes, insulin-requiring diabetes; history of orthopedic or surgical disease interfering with walking; recent infection; chronic corticoids use; inability to perform the 6MWT exactly and 6MWT counterindications; ${ }^{6}$ unstable angina or myocardial infarction during the previous month; resting heart rate $\geq 120 \mathrm{bpm}$, resting systolic or diastolic pressure, $\geq 180 \mathrm{mmHg}$ and $\geq 100 \mathrm{mmHg}$, respectively.

\section{Sample sizes \\ NIDDM patient group}

Sample size was calculated according to the following predictive equation: ${ }^{15} \mathrm{n}=\left(\mathrm{Z}^{2} \times \mathrm{p} \times \mathrm{q}\right) / \Delta^{2}$, where $n$ was the number of required NIDDM patients, $Z$ was the $95 \%$ confidence level $(=1.96)$, q was equal to $1-p, \Delta$ was the precision $(=10 \%)$, and $\mathrm{p}$ was the estimation of the 6MWD decline or submaximal aerobic capacity induced by NIDDM. According to studies, $48 \%(P=0.48)$ of older non-disabled diabetic patients at baseline developed functional limitations over a 7-year follow-up. ${ }^{16}$ The sample size was thus 96 . 


\section{Control groups}

We recruited three CGs over 40 years of age. They were tested in our department over the same period as the PG.

CG1: healthy nonobese and nonsmoker subjects ( 87 males and 87 females).

CG2: nondiabetic obese subjects free from comorbidities (17 males and 38 females).

These two CGs were recruited as a part of current protocols aiming to evaluate the submaximal exercise capacity of narghile smokers ${ }^{17}$ and obstructive-sleep-apnea patients. ${ }^{18}$

CG3: Nondiabetic "all comers" subjects (37 males and 22 females) adressed to our department for 6MWT, indicated as preoperative assessment, or faced with various diseases (especially cardiorespiratory diseases).

\section{Medical and physical activity questionnaires}

A medical questionnaire recommended for epidemiological research was used to assess subject characteristics (schooling level [SL] and occupational status, smoking, medical, surgical, and gynecologic-obstetric histories, and medication use)..$^{19}$

Two SLs were defined: low (illiterate, primary education) and high (secondary and university education). Two socioeconomic levels (SEL) were defined according to occupational status: ${ }^{14}$ low (eg, unskilled worker, jobless) and high (eg, skilled worker, farmer, manager).

Cigarette and narghile usage was evaluated, respectively, in pack-years (PY) and narghile-years (NY). ${ }^{20}$ Two groups of cigarette ( 0 , no [use $<2 \mathrm{PY}$ ]; 1 , yes [use $\geq 2 \mathrm{PY}])$ and narghile ( 0 , no [use $<1 \mathrm{NY})$, ]; 1 , yes [use $\geq 1 \mathrm{NY}$ ]) users were defined. Narghile (water pipe that enables the smoking of a tobacco preparation burned by charcoal embers; the smoke is cooled by passing through water before being inhaled) use alters lung capacity and therefore cardiorespiratory fitness. ${ }^{21,22}$

A translated version of the Voorrips ${ }^{23}$ physical activity questionnaire was filled out by each subject, and household, sporting, and leisure activities were evaluated to yield a total physical activity score (low $<9.4$, moderate 9.4-16.5, and high $>16.5) .{ }^{23}$ According to the total physical activity score, two groups of subjects were defined, one as sedentary (score $<9.4$ ) and one as active (score $>9.4$ ).

\section{Physical examination and parity}

Gender ( 0 , male; 1 , female) was noted and age (years) was verified by identity cards. Height $( \pm 0.01 \mathrm{~m})$ was measured with a height gauge with shoes removed, heels joined, and back straight. Weight $( \pm 1 \mathrm{~kg})$ was measured, and the body mass index (BMI, weight $/ \mathrm{height}^{2}, \mathrm{~kg} / \mathrm{m}^{2}$ ) was calculated. The following definitions were adopted: ${ }^{24}$ underweight (BMI < 18.5), normal weight (BMI 18.5-24.9), overweight (BMI 25.0-29.9), and obese (BMI $\geq 30.0$ ); with three classes: moderated (BMI 30.0-34.9), marked (BMI 35.0-39.9), and extreme (BMI $\geq 40.0$ ). Two patient groups were defined $(0$, nonobese $[\mathrm{BMI}<30] ; 1$, obese $[\mathrm{BMI} \geq 30])$.

Parity referred to the number of offspring. Two parity subgroups were identified: low and high (parity $<5$ and $\geq 5$, respectively). ${ }^{14}$

\section{Electrocardiogram (ECG) and absolute cardiovascular disease risk (ACVDR) score}

A 12-lead resting ECG was performed at baseline. Left ventricular hypertrophy was retained when the SokolowLyon index was higher than $35 \mathrm{~mm} .{ }^{25}$ The ACVDR is the summation of the risk factors, each one being regarded as binary (present or absent) and having an identical weight (Appendix Table 1). An abnormal reading was not considered as a reason for excluding patients.

\section{Metabolic data and definitions and diagnosis of NIDDM}

Glycemia (mmol/L), total cholesterol $(\mathrm{mmol} / \mathrm{L})$, and high-density-lipoprotein cholesterol (HDL-C, mmol/L) were quantified by spectrophotometry. Triglycerides $(\mathrm{mmol} / \mathrm{L})$ were quantified by the enzymatic colorimetric method. Low-density-lipoprotein cholesterol (LDL-C, mmol/L) was calculated. ${ }^{26} \mathrm{HbA}_{1 \mathrm{c}}$ (percentage) was quantified on hemolysed total blood (turbidimetric inhibition immunoassay).

NIDDM diagnosis was done according to international criteria: ${ }^{27}$ clinical signs of diabetes and randomly measured glycemia $\geq 11.11 \mathrm{mmol} / \mathrm{L}$ or glycemia 2 hours after a caused oral hyperglycemia $\geq 11.11 \mathrm{mmol} / \mathrm{L}$ or a twice fasting glycemia $\geq 7.00 \mathrm{mmol} / \mathrm{L}$.

The following metabolic definitions were applied. A rate of $\mathrm{HbA}_{1 \mathrm{c}}>7 \%$ shows an unbalanced NIDDM during the last 3 months, ${ }^{9}$ and two groups of patients were identified ( 0 , unbalanced; 1 , balanced). Triglycerides $\geq 1.7 \mathrm{mmol} / \mathrm{L}$ and/or HDL-C $<1 \mathrm{mmol} / \mathrm{L}$ and/or LDL-C $\geq 4.1 \mathrm{mmol} / \mathrm{L}$ diagnoses "measured" dyslipidemia, ${ }^{26}$ and two groups of patients were defined ( 0 , measured dyslipidemia; 1 , no measured dyslipidemia). 


\section{MWT procedure, dyspnea evaluation, applied definitions}

The 6MWT was conducted according to a standardized protocol. ${ }^{6}$ The test was conducted along a seldom-traveled, flat, straight corridor (40 m long, marked every $1 \mathrm{~m}$ with cones to indicate turnaround points) with a hard surface. To minimize intraday variability, temperature effects, and biological rhythms, the 6MWT was performed between 8 am and $10 \mathrm{am}$, a period characterized by a stable ambient temperature of $16^{\circ} \mathrm{C}-20^{\circ} \mathrm{C}$. All subjects performed the $6 \mathrm{MWT}$ for the first time with no warm-up period and no encouragement. Subjects were told to avoid vigorous exercise in the 2 hours prior to testing, to wear comfortable clothes and appropriate walking shoes, and to continue their usual medication. ${ }^{6}$ The subjects sat in a chair located near the starting position for at least 10 minutes before the test started. During this time, dyspnea (visual analogue scale [VAS]), heart rate, and oxyhemoglobin saturation (oxy-sat) (finger pulse oximeter; Nonin Medical, Minneapolis, MN) and systolic and diastolic pressures (SP, DP, respectively) were measured at rest $\left({ }_{\text {rest }}\right)$. The test instructions to the subjects were those recommended by the American Thoracic Society. ${ }^{6}$ At the end $\left(_{\text {end }}\right)$ of the 6MWT, the same data, in addition to 6MWD, were measured. Recommended reasons for immediately stopping the 6MWT include the following: chest pain, intolerable dyspnea, leg cramps, staggering, diaphoresis, and pale or ashen appearance. ${ }^{6}$ In addition to 6MWD ( $\mathrm{m}, \%$ ), dyspnea, SP and DP (mmHg), heart rate (bpm, \% of predicted maximal heart rate $[=208-0.7 \times$ age $]$, oxy-sat, delta oxy-sat $\left[\Delta\right.$ oxy-sat $=$ oxy-sat $\left\{\begin{array}{r}\text { rest-end } \\ \}\end{array}\right]$, and the number of stops during the $6 \mathrm{MWT}$ were noted/calculated. The $6 \mathrm{MWD}$ reference values were calculated according to local norms: ${ }^{14} 6 \mathrm{MWD}(\mathrm{m})=720.50-160.27 \times$ gender $(0$, male; 1 , female $)-5.14 \times$ age (years) $-2.23 \times$ weight $(\mathrm{kg})+272.00 \times$ height $(\mathrm{m})$.

Since the 6MWT evaluates the integrated answer of the cardiorespiratory and muscular chain, ${ }^{6}$ we calculated the "estimated age" of this chain: ${ }^{14}$ estimated "cardiorespiratory and muscular chain" age (years) $=140.1751-0.1945 \times$ measured 6MWD $(\mathrm{m})-31.1809 \times$ gender $(0$, male; 1 , female $)-0.4338 \times$ weight $(\mathrm{kg})+52.9183 \times$ height $(\mathrm{m})$.

Dyspnea during the 6MWT was evaluated by VAS, which allows an easy evaluation of exercise dyspnea. ${ }^{28}$ It is about an open segment whose two ends are the absence of breathlessness and the maximum breathlessness. It was built on a slate for writing with dry erasable felt. Subjects read a standardized text in Arabic explaining dyspnea (or were read to, if they were illiterate) before each 6MWT.
At the beginning and right at the end of the 6MWT, the subject indicated his level of breathlessness by marking with his index finger a vertical feature on the VAS. Dyspnea was then quantified from zero (no breathlessness) to ten (maximum of breathlessness).

The following definitions were applied:

- A 6MWD lower than $82 \%$ was considered a "clinically significant abnormal value" and showed walk intolerance. $^{29}$

- Stopping during the 6MWT was regarded as an intolerance sign. ${ }^{14}$

- A $\Delta$ oxy-sat $>5$ points defines a "clinically significant desaturation." 14

- Any dyspnea ${ }_{\text {end }}>5 / 10$ was considered as "clinically significant" and showed walk intolerance. ${ }^{28}$

- A heart rate end $<60 \%$ was considered a chronotropic insufficiency. ${ }^{14}$

\section{Study conduct}

First visit (day 1): presentation of the patient to the Physiology Department, signature of consent, medical and physical activity questionnaires, anthropometric data, and baseline ECG.

Second visit (day 2): fasting blood sample, food intake (a cup of mineral water and some dates), VAS explanation; resting dyspnea, blood pressure, oxy-sat and heart rate, checks of the absence of 6MWT contraindications, 6MWT practice between 8 am and $10 \mathrm{am}$.

\section{Data analysis}

\section{Expression modes of results}

The Kolmogorov-Smirnov test was used to analyse distribution of variables. ${ }^{15}$ When the distribution is normal and the variances are equal, the results are expressed by their means \pm standards deviations (SD). If the distribution isn't normal, the results are expressed by their medians (first-third quartiles). The chi-squared test was used to compare percentages.

\section{NIDDM PG: comparison of 6MWT measured data, univariate and multiple regression analysis (influencing factors)}

The dependent variable (6MWD) was normally distributed. Student's $t$-test was used to compare measured versus theoretical 6MWD, resting versus $6 \mathrm{MWT}_{\text {end }}$ data, and to evaluate the associations between measured 6MWD (m) and categorical variables $(0$, no; 1 , yes $)$ for cigarette or narghile use, chronic respiratory disease, arterial hypertension, dyslipidemia, cardiovascular diseases, thyroid dysfunction, diabetic retinopathy, history of abdominopelvic and/or thoracic and/or neurological 
surgeries, beta-blocker or diuretic use, sedentary status, obesity group, diabetes balance, measured dyslipidemia, and left ventricular hypertrophy; (0, low; 1 , high) for SEL, SL, parity, and ( 0 , male; 1 , female) for gender.

Pearson product-moment correlation $(r)$ evaluated the associations between the measured 6MWD (m) and continuous measures (physical activity score, age [years], weight $[\mathrm{kg}]$, height $[\mathrm{m}], \mathrm{BMI}\left[\mathrm{kg} / \mathrm{m}^{2}\right]$, parity [numerical], fasting glycemia $[\mathrm{mmol} / \mathrm{L}], \mathrm{HbA}_{1 \mathrm{c}}[\%]$, triglycerides $[\mathrm{mmol} / \mathrm{L}]$, total cholesterol [mmol/L], HDL-C [mmol/L], LDL-C [mmol/L], ACVDR score, dyspnea ${ }_{\text {rest }}$, heart rate ${ }_{\text {rest }}[\mathrm{bpm}], \mathrm{SP}_{\text {rest }}[\mathrm{mmHg}]$, $\mathrm{DP}_{\text {rest }}[\mathrm{mmHg}]$, and oxy-sat $\left.{ }_{\text {rest }}[\%]\right)$. The linearity of the association between the 6MWD and the continuous measures was graphically checked by plotting each regressor against 6MWD. Only significantly and linearly associated variables were entered into the model.

A linear regression model was used to evaluate the independent variables explaining the variance in 6MWD. Candidate variables were stepped into the model with a stepwise selection method. To determine entry and removal from the model, significance levels of 0.15 and 0.05 , respectively, were used. No colinearity between predictors was detected with variance inflation factors. The linear regression equation model is the following: $6 \mathrm{MWD}(\mathrm{m})=\mathrm{B}_{1} \times$ categorical variable ${ }_{1}+\mathrm{B}_{2} \times$ categorical variable $_{2}+\mathrm{B}_{\mathrm{n}} \times$ categorical variable $_{\mathrm{n}}+\mathrm{B}_{\times 1} \times$ continuous variable $_{1}+$ $\mathrm{B}_{\times 2} \times$ continuous variable ${ }_{2}+\mathrm{B}_{\times_{\mathrm{n}}} \times$ continuous variable $\mathrm{n}_{\mathrm{n}}+$ constant. $\mathrm{B}$ is the nonstandardized regression coefficient.

\section{Comparison of NIDDM PG versus CG data}

$t$-tests and chi-squared tests were used to compare quantitative data and percentages, respectively. In the same way, an analysis of variance was carried out between the four groups.

Analyses were carried out using Statistica software (Statistica Kernel version 6; StatSoft, Paris, France). Significance was set at the 0.05 level.

\section{Results}

\section{Patient group: noninclusion criteria, clinical, anthropometric, and metabolic characteristics}

An initial sample of 123 volunteer adults was examined. Noninclusion criteria, presented in detail in the Appendix, were found in 23 subjects.

Table 1 exposes the clinical, anthropometric, and metabolic characteristics of the NIDDM PG. Compared to males, there are significantly fewer female cigarette or narghile users, more females having thyroid dysfunction or with surgical history, or having low SEL, SL, or having sedentary status, there are fewer overweight females, but a higher percentage of obese females. Compared to males, females have a significantly higher BMI and LDL-C level, a lower ACVDR score and are significantly shorter.

The 6MWD of the 45 females and 55 males, according to age-group, is shown in Appendix Figure 1. Few older patients aged 65 years and more are included (four females and four males).

Additional information about the PG total sample characteristics are detailed in the Appendix.

\section{PG: 6MWT data and profile}

The 6MWT data are shown in Table 2. The total-sample measured 6MWD $(566 \pm 81 \mathrm{~m})$ was significantly lower than the theoretical one $(90 \% \pm 12 \%)$. This difference of about $86 \mathrm{~m}$ was observed only in males. For females, males, and total sample, and compared to resting data, there was a significant increase in $6 \mathrm{MWT}_{\text {end }} \mathrm{SP}, \mathrm{DP}$, and dyspnea. Oxy-sat significantly decreased only in males.

NIDDM patient profile during the 6MWT were as follows: $2 \%$ (1\% females) stopped once during the 6MWT; $4 \%$ ( $2 \%$ females) showed a clinically significant desaturation; $12 \%$ ( $7 \%$ females) expressed a clinically significant dyspnea $_{\text {end }} ; 21 \%$ (10\% females) had a chronotropic insufficiency; and 23\% (2\% females) had an abnormal 6MWD.

\section{PG: univariate and multiple regression analysis: influencing factors}

Gender significantly affected the 6MWD (Table 2). On average, the 6MWD values were $96 \mathrm{~m}$ greater (significant) in males when compared to females. This difference applies to patients aged between 45 and 60 years and more than 65 years (Appendix Figure 1).

Univariate analysis between 6MWD and patient data is shown in the Appendix Table 2. In the total sample, the following categorical variables significantly affected the 6MWD: cigarette use, surgical history, SEL, SL, physical activity level, and obesity. In the total sample, 6MWD was significantly correlated $(P<0.05)$ with the following continuous variables: age; height; BMI; daily, sporting, leisure, and physical activity scores; $\mathrm{ACVDR}$ score; $\mathrm{SP}_{\text {rest }}$; and oxy-sat ${ }_{\text {rest }}$. Several factors did not independently explain the variability of 6MWD, such as metabolic data.

Table 3 presents the cumulative determination coefficient $\left(r^{2}\right)$ of the independent factors included in the 6MWD forward linear stepwise multiple regressions. For the total sample, 
Table I Clinical, anthropometric, and metabolic characteristics of the non-insulin-dependent diabetes mellitus patient group

\begin{tabular}{|c|c|c|c|}
\hline & Females $(n=45)$ & Males $(n=55)$ & Total sample $(n=100)$ \\
\hline \multicolumn{4}{|c|}{ Smoking status, medical, surgical and obstetric history, current medication (n) } \\
\hline Cigarette use & 1 & $37 * *$ & 38 \\
\hline Narghile use & 0 & $8^{* *}$ & 8 \\
\hline Chronic respiratory diseases & 3 & 7 & 10 \\
\hline Arterial hypertension & 20 & 17 & 37 \\
\hline Dyslipidemia & 8 & 6 & 14 \\
\hline Cardiovascular diseases & 3 & 4 & 7 \\
\hline Dysthyroid & 4 & $0 * *$ & 4 \\
\hline Diabetic retinopathy & 3 & 5 & 8 \\
\hline Renal failure & 0 & I & 1 \\
\hline Anemia & 2 & I & 3 \\
\hline Surgical history & 17 & $8 * *$ & 25 \\
\hline Low parity & 34 & & \\
\hline Beta-blocker use & 6 & 4 & 10 \\
\hline Diuretic use & 3 & I & 4 \\
\hline Bronchodilator use & 2 & 0 & 2 \\
\hline \multicolumn{4}{|c|}{ Socioeconomic, schooling, and physical activity levels (n) } \\
\hline Low socioeconomic level & 27 & $9 * *$ & 36 \\
\hline Low schooling level & 22 & $15 * *$ & 37 \\
\hline Sedentary status & 32 & $18 * *$ & 50 \\
\hline \multicolumn{4}{|c|}{ Daily, sporting, leisure, and physical activity scores, parity [median (I st-3rd quartile)] } \\
\hline \multicolumn{4}{|c|}{ Activities } \\
\hline Daily & $2(2-2)$ & $\mathrm{I}(\mathrm{I}-2)^{*}$ & $2(1-2)$ \\
\hline Sporting & $2(0-7)$ & $8(3-13)^{*}$ & $6(1-11)$ \\
\hline Leisure & $I(I-2)$ & $2(I-4)^{*}$ & $2(I-3)$ \\
\hline Physical & $6(4-11)$ & $13(7-18)^{*}$ & $9(5-15)$ \\
\hline Parity (numerical) & $3(2-4)$ & & \\
\hline \multicolumn{4}{|c|}{ Anthropometric data (mean \pm SD) } \\
\hline Age (years) & $55 \pm 8$ & $54 \pm 8$ & $54 \pm 8$ \\
\hline Weight (kg) & $80 \pm 16$ & $82 \pm 11$ & $81 \pm 14$ \\
\hline Height (m) & $1.56 \pm 0.06$ & $1.70 \pm 0.06 *$ & $1.64 \pm 0.09$ \\
\hline Body mass index $\left(\mathrm{kg} / \mathrm{m}^{2}\right)$ & $33 \pm 6$ & $28 \pm 4^{*}$ & $30 \pm 5$ \\
\hline \multicolumn{4}{|c|}{ Metabolic data and absolute cardiovascular disease risk (ACVDR) score (mean \pm SD) } \\
\hline Fasting glycemia (mmol/L) & $9.50 \pm 3.24$ & $9.47 \pm 2.72$ & $9.49 \pm 2.95$ \\
\hline Glycated hemoglobin (\%) & $8 \pm 2$ & $8 \pm 2$ & $8 \pm 2$ \\
\hline Triglycerides (mmol/L) & $1.47 \pm 0.78$ & $1.86 \pm 1.50$ & $1.68 \pm 1.24$ \\
\hline Total cholesterol (mmol/L) & $5.04 \pm 1.01$ & $4.78 \pm 0.78$ & $4.90 \pm 0.89$ \\
\hline HDL-C (mmol/L) & $1.08 \pm 0.30$ & $1.06 \pm 0.32$ & $1.07 \pm 0.31$ \\
\hline LDL-C (mmol/L) & $3.27 \pm 0.92$ & $2.87 \pm 0.73 *$ & $3.05 \pm 0.85$ \\
\hline ACVDR score & $2 \pm 1$ & $4 \pm I^{*}$ & $3 \pm 1$ \\
\hline \multicolumn{4}{|c|}{ Normal weight, overweight, and obese (number) } \\
\hline Normal weight & 5 & 9 & 14 \\
\hline Overweight & 9 & $29 * *$ & 38 \\
\hline \multicolumn{4}{|l|}{ Obese } \\
\hline Moderate & 16 & 15 & 31 \\
\hline Marked & 10 & $2 * *$ & 12 \\
\hline Extreme & 5 & $0 * *$ & 5 \\
\hline Three degrees of obesity & 31 & $17 * *$ & 48 \\
\hline \multicolumn{4}{|c|}{ Metabolic characteristics (number) } \\
\hline Uncontrolled diabetes & 25 & 33 & 58 \\
\hline “Measured” dyslipidemia & 30 & 37 & 67 \\
\hline
\end{tabular}

Notes: $* P$ (probability, $t$-test $)<0.05$, females vs males; $* * P$ (probability, chi-squared test $)<0.05$, females vs males.

Abbreviations: HDL-C, high-density-lipid cholesterol; LDL-C, low-density-lipid cholesterol. 
Table 2 Six-minute walk test (6MWT) data of the non-insulin-dependent diabetes mellitus patient group

\begin{tabular}{|c|c|c|c|c|c|c|}
\hline & \multicolumn{2}{|c|}{ Females $(n=45)$} & \multicolumn{2}{|l|}{ Males $(n=55)$} & \multicolumn{2}{|c|}{ Total sample $(n=100)$} \\
\hline & Rest & End & Rest & End & Rest & End \\
\hline \multicolumn{7}{|l|}{ Heart rate } \\
\hline (bpm) & $81 \pm 12$ & $118 \pm 19^{\#}$ & $78 \pm 13$ & $113 \pm 20^{\#}$ & $79 \pm 13$ & $115 \pm 19^{\#}$ \\
\hline (\%) & $47 \pm 7$ & $69 \pm 10^{\#}$ & $46 \pm 8$ & $67 \pm 12^{\#}$ & $46 \pm 7$ & $68 \pm 1 I^{\#}$ \\
\hline \multicolumn{7}{|l|}{ 6MWD } \\
\hline$(\mathrm{m})$ & $513 \pm 63$ & & $609 \pm 67^{*}$ & & $566 \pm 81$ & \\
\hline (\%) & $98 \pm 11$ & & $84 \pm 9^{*, \dagger}$ & & $90 \pm 12^{\dagger}$ & \\
\hline Oxy-sat (\%) & $98(97-98)$ & $98(97-98)$ & $98(98-98)$ & $98(97-98)^{\#}$ & $98(97-98)$ & 98 (97-98) \\
\hline Systolic pressure $(\mathrm{mmHg})$ & $130(120-140)$ & $150(140-160)^{\#}$ & $130(\mid 20-140)$ & $150(130-160)^{\#}$ & $130(120-140)$ & $150(140-160)^{\#}$ \\
\hline Diastolic pressure $(\mathrm{mmHg})$ & $80(80-80)$ & $80(80-90)^{\#}$ & $80(70-80)$ & $80(80-90)^{\#}$ & $80(75-80)$ & $80(80-90)^{\#}$ \\
\hline Dyspnea (VAS) & $0(0-0)$ & $2(I-4)^{\#}$ & $0(0-0)$ & $2(0-3)^{\#}$ & $0(0-0)$ & $2(I-3)^{\#}$ \\
\hline
\end{tabular}

Notes: *P (probability, $t$-test) $<0.05$, females vs males; $\#$ (probability, $t$-test) $<0.05$, "rest vs end" $6 M W T$; ${ }^{\dagger} P$ (probability, $t$-test) $<0.05$, "measured vs theoretical" 6MWD; data are means for heart rate and 6MWD and medians (Ist-3rd quartiles) for others.

Abbreviations: 6MWD, 6-minute walk distance; VAS, visual analog scale; bpm, beats per minute; oxy-sat, oxyhemoglobin saturation.

gender, age, leisure activity score, obesity, SEL, cigarette use, and oxy-sat ${ }_{\text {rest }}$ were independent predictors, and up to $58 \%$ of the $6 \mathrm{MWD}$ variability could be explained with the proposed model in Table 3.

\section{PG: "cardiorespiratory and muscular chain" estimated age}

In the total sample, the "cardiorespiratory and muscular chain" estimated age was significantly higher than the chronological age ( $68 \pm 16$ years versus $54 \pm 8$ years, respectively; $P<0.05)$. This difference existed only in males ( $76 \pm 13$ years versus $54 \pm 8$ years, respectively; $P<0.05$ ).

\section{PG: characteristics of patients distributed according to the 6MWD (normal versus abnormal 6MWD)}

Table 4 presents the characteristics of the two groups of patients with abnormal 6MWD (21 males, 2 females) and normal 6MWD (34 males, 43 females). Compared to the group having a normal $6 \mathrm{MWD}(94 \% \pm 10 \%)$, the group having abnormal $6 \mathrm{MWD}(76 \% \pm 5 \%)$, is significantly younger and taller, contains a significantly higher percentage of patients using cigarettes or having measured dyslipidemia, and has a higher ACVDR score.

\section{PG: parity effect}

In the entire female population $(n=45)$, a negative univariate linear correlation was found between parity (numerical) and 6MWD $(r=-0.44 ; P<0.05)$, and on average the $6 \mathrm{MWD}$ value was $61 \mathrm{~m}$ greater in females having low parity (Appendix Table 2). Parity also appeared to be a negative independent variable included in the forward linear stepwise multiple regression model for 6MWD (Table 3).

\section{Comparison of NIDDM PG versus CG data}

Table 5 presents the characteristics of the PG and CGs. Analysis of the total samples 6MWDs revealed that compared to CG1 (636 $\pm 112 \mathrm{~m}, 100 \% \pm 9 \%)$, to CG2 $(100 \% \pm 8 \%)$, and to CG3 (507 $\pm 129 \mathrm{~m}, 83 \% \pm 14 \%)$, the PG (566 $\pm 81 \mathrm{~m}$, $90 \% \pm 12 \%$ ) had a significantly lower 6MWD (m, \%), lower 6MWD (\%), and higher 6MWD (m, \%), respectively. Detailed information appears in the Appendix.

\section{Discussion}

The 6MWT profile of a large group of NIDDM patients older than 40 years was evaluated. It seems that NIDDM accelerates "cardiorespiratory and muscle chain" aging, with $23 \%$ of patients having an abnormal 6 MWD. Impaired submaximal aerobic capacity is more pronounced in females and/or in the elderly and/or in subjects having low leisure activity score and/or in obese patients and/or in patients having low SEL and/or in cigarette smokers and/or in subjects having low resting oxy-sat. Compared to healthy nonobese and nonsmoking or nondiabetic obese control groups, NIDDM patients group had a significantly lower 6MWD.

\section{Study design and statistical analysis}

Detailed discussion of the recruitment method, the inclusion and noninclusion criteria, the sample size, and the questionnaires used appears in the Appendix. The number of measures and comparisons $(n=36)$ was too large for the number of 
Table 3 Independent variables included in the forward linear stepwise multiple regression model for the 6-minute walk distance (6MWD) of the non-insulin-dependent diabetes mellitus patient group

\begin{tabular}{|c|c|c|c|}
\hline Independent variables & B & $95 \% \mathrm{Cl}$ & Cumulative $r^{2}$ \\
\hline \multicolumn{4}{|l|}{ Females $(n=45)$} \\
\hline Constant & 714.54 & $630.01-799.07$ & \\
\hline Age (years) & -3.51 & -5.12 to -1.90 & 0.297 \\
\hline Socioeconomic level (0, low; I, high) & 29.44 & $2.79-56.09$ & 0.382 \\
\hline Parity (numerical) & -6.09 & $-12.85-0.67$ & 0.413 \\
\hline \multicolumn{4}{|l|}{ Males $(n=55)$} \\
\hline Constant & -234.62 & $-1307.93-838.69$ & \\
\hline Systolic pressure $_{\text {rest }}(\mathrm{mmHg})$ & -0.90 & $-2.03-0.24$ & 0.091 \\
\hline Leisure activity score & 8.88 & $3.40-14.36$ & 0.166 \\
\hline Cigarette use* $(0$, no; I, yes $)$ & -38.35 & -65.73 to -10.98 & 0.234 \\
\hline Oxy-sat $_{\text {rest }}(\%)$ & 10.90 & $0.24-1.56$ & 0.292 \\
\hline Physical activity score & -1.80 & $-3.89-0.28$ & 0.317 \\
\hline Age (years) & -1.57 & $-3.39-0.26$ & 0.344 \\
\hline \multicolumn{4}{|l|}{ Total sample $(n=100)$} \\
\hline Constant & -105.48 & $-973.64-762.69$ & \\
\hline Gender ( 0 , male; I, female) & -73.94 & -101.23 to -46.65 & 0.350 \\
\hline Age (years) & -3.25 & -4.43 to -2.07 & 0.446 \\
\hline Leisure activity score & 7.33 & $3.22-11.45$ & 0.485 \\
\hline Obesity** ( 0, no; I, yes) & -35.57 & -55.35 to -15.79 & 0.528 \\
\hline Socioeconomic level (0, low; I, high) & 32.86 & II.84-53.87 & 0.554 \\
\hline Cigarette use* $(0$, no; I, yes) & -27.67 & -52.49 to -2.86 & 0.568 \\
\hline Oxy-sat $_{\text {rest }}(\%)$ & 8.89 & $0.17-17.61$ & 0.580 \\
\hline
\end{tabular}

Notes: $95 \% \mathrm{Cl}$, $95 \%$ confidence interval around each B; *cigarette use: 0 , no (use $\leq 2$ pack-years); I, yes (use $>2$ pack-years); **obesity: 0 , no (BMI < 30 kg/m²); I, yes $\left(B M I \geq 30 \mathrm{kgm}^{2}\right)$; proposed model for the NIDDM total sample: 6 MWD $(\mathrm{m})=-73.94 \times$ gender $(0$, male, I, female $)-3.25 \times$ age $($ years $)+7.33 \times$ leisure-activity score -

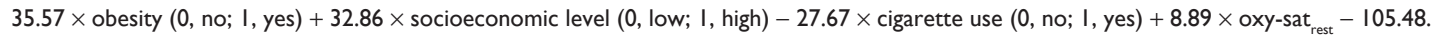

Abbreviation: oxy-sat, oxyhemoglobin saturation.

participants included in the present study, usually one variable for ten participants.

\section{Justification of the 6MWT choice to evaluate submaximal aerobic capacity}

Exercise tolerance is usually expressed in terms of maximal oxygen consumption $\left(\dot{\mathrm{V}}_{2 \max }\right)$ measured during a cardiorespiratory test realized under optimal safety conditions and in the presence of a physician and a technician. ${ }^{30}$ However, the cardiorespiratory test has some drawbacks. First, it uses expensive and sophisticated equipment, demanding that it be operated by highly qualified personnel. ${ }^{6}$ Thus the repeated use of such a test for assessment of exercise training represents a significant financial cost. ${ }^{6,31}$ Second, the complexity of the examination and its interpretation does not allow the patient to have a quick and convenient representation of its progress. ${ }^{6}$ Finally, this test can't be done on a large scale. ${ }^{6}$ These drawbacks lead us to turn to the tests called "low-tech," such as the 6MWT (reliable, valid, safe, inexpensive, feasible on a large scale, can be performed by a physician, or a nurse, physiotherapist, or teacher of adapted physical activities). It is used to assess exercise tolerance not only of chronic respiratory diseases but also those with hear ${ }^{32}$ or metabolic ${ }^{12,13}$ diseases. Another justification for our choice is that the 6MWT quantifies the ability to perform activities of daily life, familiar to subjects, and therefore supports the idea of submaximal activity. Finally, it is preferable to start as part of the assessment of exercise tolerance, by the practice of 6MWT and in case of an abnormal $6 \mathrm{MWD}$, the cardiorespiratory test is largely indicated. ${ }^{6}$

\section{Precautions taken during 6MWT}

The 6MWT was performed in the open air in a corridor of $40 \mathrm{~m}$ length. ${ }^{6}$ Enright et al, ${ }^{12}$ and Ingle et al, ${ }^{13}$ used, respectively, corridors of $30 \mathrm{~m}$ and $15 \mathrm{~m}$. Detailed discussion of the precautions taken during the 6MWT appears in the Appendix.

\section{Characteristics of NIDDM PG}

Our NIDDM sample can be considered as representative of the Northwest African population with NIDDM. Indeed, in our study, the frequency of risk factors and certain comorbidities observed were similar to those reported in other studies (Appendix Table 3). 
Table 4 Characteristics of non-insulin-dependent diabetes mellitus patients, divided according to their 6MWD (Group I, abnormal 6MWD; Group 2: normal 6MWD)

\begin{tabular}{|c|c|c|}
\hline & $\begin{array}{l}\text { Group I } \\
(n=23)\end{array}$ & $\begin{array}{l}\text { Group } 2 \\
(n=77)\end{array}$ \\
\hline \multirow{2}{*}{\multicolumn{3}{|c|}{$\begin{array}{l}\text { Smoking, physical activity and absolute cardiovascular disease } \\
\text { risk (ACVDR) scores, anthropometric, metabolic and resting }\end{array}$}} \\
\hline & & \\
\hline \multicolumn{3}{|l|}{ 6MWT data (mean \pm SD) } \\
\hline Cigarette use (pack-years) & $21 \pm 13$ & $19 \pm 14$ \\
\hline Narghile use (narghile-years) & $26 \pm 49$ & $20 \pm 28$ \\
\hline Age (years) & $51 \pm 6$ & $55 \pm 8^{*}$ \\
\hline Weight (kg) & $84 \pm 12$ & $80 \pm 14$ \\
\hline Height (m) & $1.69 \pm 0.06$ & $1.63 \pm 0.09 *$ \\
\hline Body mass index $\left(\mathrm{kg} / \mathrm{m}^{2}\right)$ & $30 \pm 4$ & $30 \pm 5$ \\
\hline Glycated hemoglobin (\%) & $7.75 \pm 2.16$ & $7.88 \pm 2.12$ \\
\hline Fasting glycemia (mmol/L) & $9.69 \pm 3.00$ & $9.42 \pm 2.95$ \\
\hline Triglycerides (mmol/L) & $2.00 \pm 1.30$ & $1.59 \pm 1.21$ \\
\hline Total cholesterol (mmol/L) & $4.70 \pm 0.73$ & $4.96 \pm 0.93$ \\
\hline HDL-C (mmol/L) & $0.97 \pm 0.20$ & $1.10 \pm 0.33$ \\
\hline LDL-C (mmol/L) & $2.81 \pm 0.83$ & $3.12 \pm 0.84$ \\
\hline Physical activity score & $13 \pm 7$ & $10 \pm 6$ \\
\hline ACVDR score & $4 \pm 1$ & $3 \pm 1 *$ \\
\hline Dyspnea (VAS) & $0 \pm 0$ & $0 \pm 0$ \\
\hline Heart rate (\%) & $46 \pm 8$ & $47 \pm 7$ \\
\hline Systolic pressure (mmHg) & $129 \pm 9$ & $130 \pm 14$ \\
\hline Diastolic pressure $(\mathrm{mmHg})$ & $80 \pm 6$ & $79 \pm 8$ \\
\hline Oxy-sat (\%) & $98 \pm 1$ & $98 \pm 1$ \\
\hline \multicolumn{3}{|l|}{ 6MWD } \\
\hline (m) & $544 \pm 55$ & $573 \pm 86$ \\
\hline (\%) & $76 \pm 5$ & $94 \pm 10 *$ \\
\hline \multicolumn{3}{|c|}{ Percentage of patients with the following characteristics } \\
\hline Cigarette use & $83 \%$ & $25 \% * *$ \\
\hline Narghile use & $17 \%$ & $5 \%$ \\
\hline Chronic respiratory diseases & $4 \%$ & $12 \%$ \\
\hline Arterial hypertension & $30 \%$ & $39 \%$ \\
\hline Cardiovascular diseases & $13 \%$ & $5 \%$ \\
\hline Diabetic retinopathy & $7 \%$ & $8 \%$ \\
\hline Surgical history & $17 \%$ & $27 \%$ \\
\hline Beta-blocker use & $0 \%$ & $13 \%$ \\
\hline Low socioeconomic level & $30 \%$ & $38 \%$ \\
\hline Low schooling level & $30 \%$ & $39 \%$ \\
\hline Sedentary status & $35 \%$ & $55 \%$ \\
\hline Obesity & $48 \%$ & $48 \%$ \\
\hline Uncontrolled diabetes & $57 \%$ & $58 \%$ \\
\hline Dyslipidemia history & $17 \%$ & $13 \%$ \\
\hline "Measured" dyslipidemia & $87 \%$ & $61 \% * *$ \\
\hline
\end{tabular}

Notes: $* P$ (probability, $t$-test) $<0.05 ; * * P$ (probability, chi-squared test) $<0.05$. Abbreviations: 6MWD, 6-minute walk distance; 6MWT, 6-minute walk test; HDL, high-density lipoprotein; LDL, low-density lipoprotein; VAS, visual analog scale; oxy-sat, oxyhemoglobin saturation.

\section{Limitations of this study}

In females, menopause and changes in hormonal status that may affect aerobic capacity ${ }^{33}$ haven't been evaluated. Passive smoking has not been studied despite its adverse effects on exercise capacity, particularly as it reduces the lungs' performance. ${ }^{34} \mathrm{We}$ didn't measure quadriceps strength or the leg length, known as 6MWD-influencing factors. ${ }^{29}$ In this study, we evaluated NIDDM patient deficiency by determining fasting glycemia, $\mathrm{HbA}_{1 \mathrm{c}}$, lipid profile, blood pressure, and ACVDR score. However, there are other biological markers such as oxidative stress, inflammation, and apoptosis, ${ }^{35-40}$ which may cause disabilities through myopathy. ${ }^{41}$ Similarly, it was desirable to measure some morphological data (lower-limb length, ${ }^{29}$ muscle biopsy data, ${ }^{41}$ or lung function ${ }^{42}$ ). As part of exploration of incapacity, it was desirable to achieve in a number of our patients a cardiorespiratory test and to evaluate the correlation between $\dot{\mathrm{VO}}_{2 \max }$ and 6MWD. As part of the exploration of social disadvantage, it was desirable to explore the QOL of our patients. However, to our knowledge, there is no validated Arabic version of the QOL questionnaire specific to NIDDM patients. ${ }^{43}$

\section{Deterioration of submaximal aerobic capacity}

Submaximal aerobic capacity of NIDDM patients seems to have deteriorated. Indeed, the measured 6MWD was $86 \mathrm{~m}$ less than the predicted one. In addition, almost one-quarter of our NIDDM patients had an abnormal 6MWD. Similarly, there were signs of walking intolerance $(2 \%$ and $12 \%$ of patients stopped the walk and expressed a clinically significant dyspnea ${ }_{\text {end }}$, respectively). Finally, compared to healthy nonobese, nonsmokers and nondiabetic obese CGs, the PG had a significantly lower 6MWD.

Another key outcome of the present study is that the NIDDM accelerates the "cardiorespiratory and muscle chain" aging. It is an unwavering argument to motivate patients to better compliance with preventive and therapeutic measures. To our knowledge, this result has never been shown before.

Twenty-one percent of our patients had an impaired chronotropic heart response. This reflects the impact of NIDDM on the activity of the sinus node during the walk. ${ }^{44}$ Moreover, the ACVDR score of the group with abnormal 6MWD was significantly higher than the group with normal 6MWD (Table 4). This is an important argument to encourage patients with NIDDM to start regular exercise. ${ }^{45}$ Indeed, the exercise training and aerobic capacity were positively related to cardiovascular profile. ${ }^{45}$

To our knowledge, only two studies have examined the submaximal aerobic capacity of NIDDM patients. ${ }^{12,13}$ The first study, conducted in 2003 by Enright et al, ${ }^{12}$ aimed to establish 6MWD norms specific to the US population aged 68 years and more ( $\mathrm{n}=2117$ subjects, $13 \%$ had NIDDM). The multiple linear regression model revealed that the NIDDM 


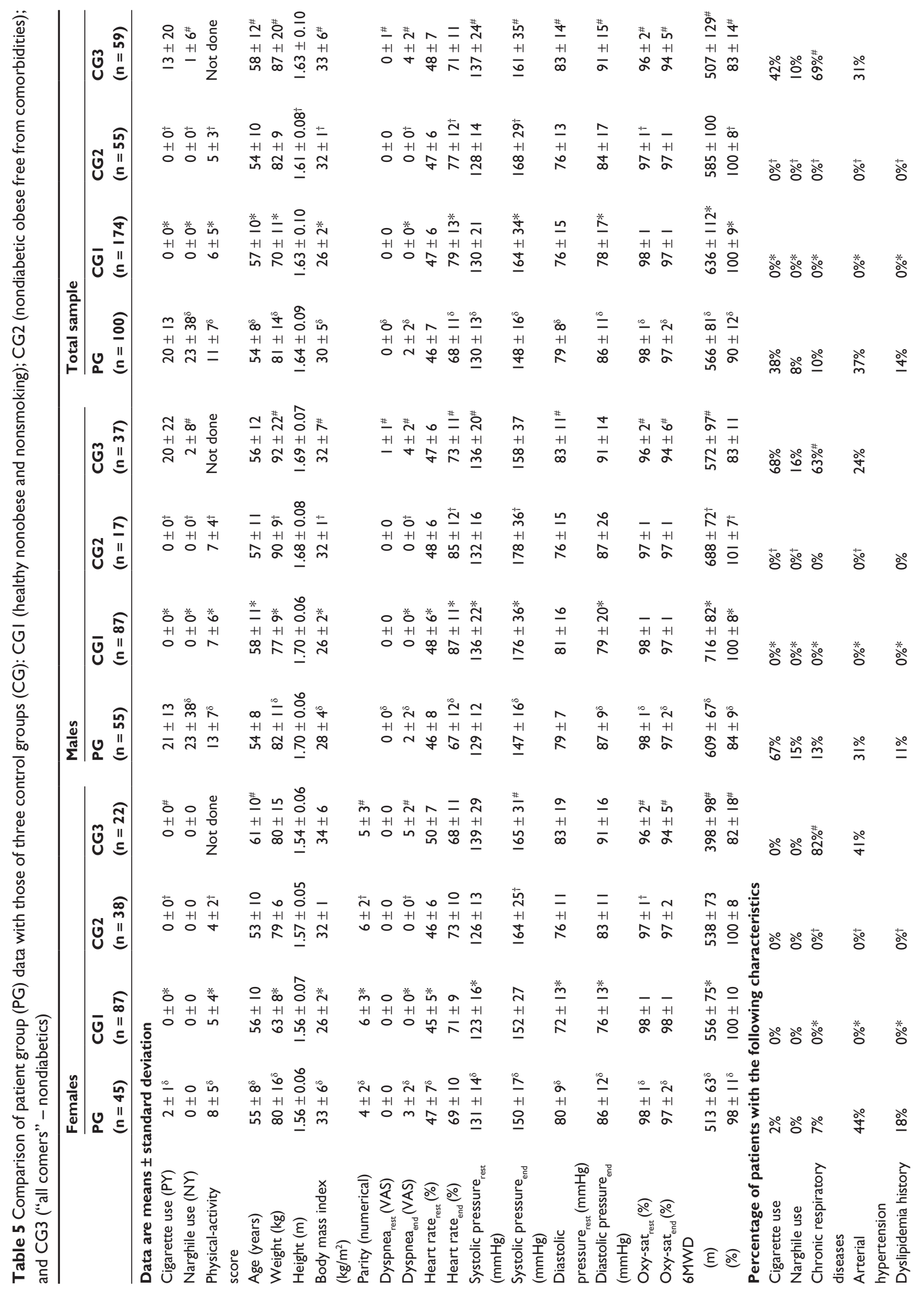




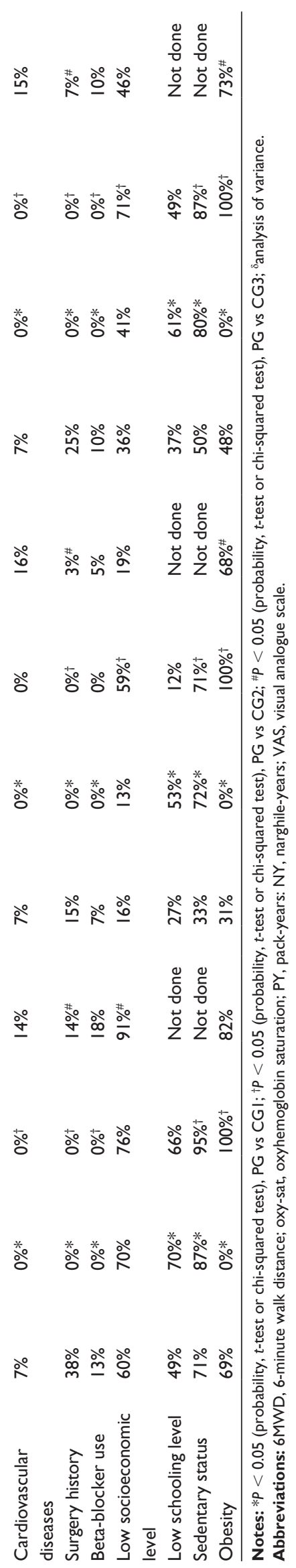

was an independent predictor that altered the 6MWD. ${ }^{12}$ These authors recommended the 6MWT to assess the impact of NIDDM and other comorbidities (cardiovascular or respiratory diseases, arthritis, cognitive dysfunction, depression, etc) on elderly submaximal aerobic capacity. ${ }^{12}$ The second study, a retrospective one, conducted in 2006 by Ingle et al, ${ }^{13}$ compared the $6 \mathrm{MWD}$ of four matched groups of patients (no statistical difference in age or gender): "heart failure with NIDDM" $(n=88)$ versus "heart failure free from NIDDM" $(\mathrm{n}=88)$, "coronary artery disease with NIDDM" $(\mathrm{n}=50)$ versus "coronary heart disease free from heart failure" $(n=50)$. These authors found that the 6MWD of the "heart failure with NIDDM" group $(238 \pm 124 \mathrm{~m})$ was significantly lower than the $6 \mathrm{MWD}$ of the "heart failure free from NIDDM" (296 $\pm 131 \mathrm{~m})$ and that the 6MWD of the "heart failure free from NIDDM" group $(231 \pm 139 \mathrm{~m})$ was significantly lower than the 6MWD of the "coronary heart disease free from heart failure" group $(283 \pm 126 \mathrm{~m}) .{ }^{13}$ These authors found that NIDDM was an independent determinant of low submaximal aerobic capacity. ${ }^{13}$

\section{How can we explain the impairment of submaximal aerobic capacity of NIDDM patients?}

The first important point of the present study is that classical biological data (fasting glycemia, $\mathrm{HbA}_{1 \mathrm{c}}$, lipid) often used to monitor the development of NIDDM don't appear as indicators of incapacity (Table 3 and Appendix Table 2). However, there is evidence that regular physical activity in NIDDM patients is associated with a significant improvement in glycemic control, particularly in $\mathrm{HbA}_{1 \mathrm{c}}{ }^{45}$ Moreover, evaluation of NIDDM patient physical training programs is mainly based on the $\mathrm{HbA}_{1 \mathrm{c}}$ changes. ${ }^{46-49}$

In the total sample (Table 5), the alteration of submaximal aerobic capacity is more pronounced in females and/or in the elderly and/or in subjects having a low leisure activity score and/or in obese patients and/or in patients having low socioeconomic level and/or in cigarette smokers and/or in subjects having low oxy-sat ${ }_{\text {rest }}$. It is important to note that the suppression of the eight patients aged 65 years and more doesn't significantly confound the total sample actual results. These factors, in addition to parity, will be analyzed one by one in the following sections.

\section{Effect of gender}

As in some healthy ${ }^{14,29}$ or patient ${ }^{12}$ adult populations, we found that females compared to males have a lower 6MWD (Table 3 and Appendix Table 2). One plausible explanation 
is that muscle mass and therefore maximum leg-muscle force is lower for females than males. ${ }^{50}$ Another plausible explanation is parity, known as a physiological factor, accelerating the healthy female's 6MWD decline. ${ }^{14}$ Indeed, among NIDDM females, in addition to age and SEL, parity appears to be an independent factor influencing 6MWD (Table 3 ). Among healthy women aged more than 40 years, the 6MWD decreased by $9.58 \mathrm{~m}$ when parity increased by one unit $(r=-0.39, P<0.05) .{ }^{14}$ In our study, NIDDM accelerated this decline, since the 6MWD of NIDDM female subjects decreased by $13.38 \mathrm{~m}$ when parity increased by one unit $(r=-0.44, P<0.05)$.

\section{Effect of age}

As in most studies of healthy ${ }^{14,29}$ or patient ${ }^{51}$ adult populations, we found that age is a predictor of 6MWD decline. The potential physical decrease observed with aging is partly due to reduced muscle mass, strength, and endurance, thus defining sarcopenia. ${ }^{14}$ Indeed, from 40 years of age, muscle mass decreases by an average of $5 \%$ per decade. ${ }^{50}$

\section{Effect of physical inactivity}

Physical inactivity significantly influences healthy subjects' 6MWD, which decreased by $2.30 \mathrm{~m}$ when the physical activity score decreased by one point. ${ }^{25}$ This decrease was more pronounced in NIDDM patients, ${ }^{52}$ since patients with low leisure-activity scores (sedentary status) had a lower 6MWD by of $7.33 \mathrm{~m}$ (Table 3 ). This result is an important argument to encourage NIDDM patients to start regular exercise. $^{40}$

\section{Effect of obesity}

Obesity, especially the marked type, is predictive of 6MWD decline. ${ }^{6,29}$ Indeed, some authors ${ }^{14}$ have shown that healthy subjects' 6MWD decreases by about $6 \mathrm{~m}$ when the BMI increases by one unit. In our study, being obese reduced 6MWD by $35.57 \mathrm{~m}$ (Table 3 ). This confirms once more the adverse effects of obesity on aerobic capacity, ${ }^{6}$ and suggests that the obesity-NIDDM association accelerates 6MWD decline. This result is an important argument to encourage NIDDM patients to start a diet and/or regular exercise. ${ }^{47}$

\section{Effect of SEL}

In a healthy Tunisian population, the SEL significantly influenced the 6MWD. ${ }^{14}$ Indeed, having a low SEL decreases the 6MWD by $12.78 \mathrm{~m} .{ }^{14}$ Our study suggests that the onset of NIDDM in subjects having a low SEL accelerates the 6MWD decline since it reaches $32.86 \mathrm{~m}$ (Table 3).

\section{Effect of smoking}

It is well known that smoking causes aerobic capacity alteration. ${ }^{53}$ In our study, being a cigarette smoker decreased 6MWD by $27.67 \mathrm{~m}$ (Table 3), and the group with abnormal 6MWD had a significantly higher percentage of cigarette smokers (Table 4). This result, which confirms once again the harmful effects of smoking, ${ }^{54}$ is a very important point to encourage NIDDM patients to stop smoking.

\section{Effect of resting oxy-sat}

In our study, the greater the oxy-sat ${ }_{\text {rest }}$ was, the greater the 6MWD was (Table 5). In many chronic diseases, desaturation during a walk is an independent prognostic marker and is associated with a significant risk of mortality. ${ }^{55,56}$ For example, in pulmonary arterial hypertension, desaturation of more than $10 \%$ increased the mortality risk by $2.9 .{ }^{56}$ In NIDDM, the clinically significant desaturation observed in $4 \%$ of our nonsmoking patients free from chronic respiratory diseases can be explained by the impact of diabetes on lung function $^{42}$ with impaired alveolar-capillary membrane. ${ }^{42}$

\section{Effect of parity}

6MWD was lower by $61 \mathrm{~m}$ in NIDDM females with high parity (Appendix Table 2). This result may be clinically relevant when interpreting 6MWT in females with NIDDM. A simple way to solve this problem would be to substract $61 \mathrm{~m}$ from the theoretical value of these females. This phenomenon may reflect the general findings about aging and parity effects on health. ${ }^{57}$ In fact, repeated gestations have been found to have potentially noxious effects on health, and several hypotheses, discussed in a previous paper, ${ }^{14}$ have been advanced (detailed discussion appears in the Appendix). Medical studies provide very little information on the influence of parity on exercise tolerance, however, and this may be a promising new direction for physiological and pathophysiological research, particularly for developing countries.

\section{Other factors explaining the submaximal aerobic capacity decline}

The aforementioned factors explain $58 \%$ of the total-sample 6 MWD variability (Table 3 ), which means that $42 \%$ of the variability remains unexplained. What other factors not evaluated in the present study may affect the NIDDM patients' 6MWD?

As was said in the sixteenth century by Paracelsus (1493-1541), who wrote that "diabetes is a systemic disease caused by the presence of an abnormal product in the blood. This would act on the kidneys and cause polyuria," 58 
NIDDM can be considered a general disease with a metabolic starting point, the main pathophysiological mechanism being insulin resistance. ${ }^{27}$ As part of this systemic disease, we can discuss the myopathy as an altering factor of the submaximal aerobic capacity. ${ }^{41}$ This could be the result of numerous alterations, the main ones being inflammation, ${ }^{35,37,39}$ apoptosis, ${ }^{38}$ oxidative stress, ${ }^{36}$ abnormal glucose and lipid or oxidative enzyme ${ }^{59}$ metabolisms, abnormal microcirculation, ${ }^{60}$ or abnormal type of fiber. ${ }^{52}$ These factors are discussed in the Appendix.

In conclusion, NIDDM seems to accelerate the decline of the submaximal aerobic capacity evaluated through 6MWT data.

\section{Acknowledgment}

The authors would like to thank Professors Bechir Saadaoui, Gouider Jeridi, Koussay Ach, Molka Chedly Chaieb, Monia Zaouali Ajina, and Sonia Rouatbi (Hospital Farhat Hached, Sousse, Tunisia) for their help.

\section{Disclosure}

The authors report no conflicts of interest in this work.

\section{References}

1. Ghannem H, Fredj AH. Epidemiological transition and cardiovascular risk factors in Tunisia [French]. Rev Epidemiol Sante Publique. 1997;45:286-292.

2. World Health Organization. non-insulin-dependent diabetes mellitus [French]. Available from: http://www.who.int/entity/mediacentre/ factsheets/fs138/fr. Accessed January 15, 2012.

3. Bouguerra R. The global diabetes pandemic: the Tunisian experience. Eur J Clin Nutr. 2007;61:160-165.

4. World Health Organization. International Classification of Functioning, Disability and Health. Geneva: WHO; 2001. Available from: http:/ www.who.int/icidh. Accessed January 15, 2012.

5. Rydén L, Standl E, Bartnik M, et al. Guidelines on diabetes, pre-diabetes and cardiovascular diseases: executive summary. The Task Force on Diabetes and Cardiovascular Diseases of the European Society of Cardiology (ESC) and of the European Association for the Study of Diabetes (EASD). Eur Heart J. 2007;28:88-136.

6. American Thoracic Society. ATS statement: guidelines for the sixminute walk test. Am J Respir Crit Care Med. 2002;16:111-117.

7. Rodbard H. AACE Diabetes mellitus clinical practice guidelines task force. Endocr Pract. 2007;13:1-31.

8. Ahmann A. Guidelines and performance measures for diabetes. Am J Manag Care. 2007;13:41-46.

9. Home P. IDF Clinical Guidelines Task Force. Global Guideline for Type 2 Diabetes. Brussels: International Diabetes Federation; 2005.

10. Neimanis L, Paterson M. Surveillance for type 2 diabetes and its complications. Can Fam Physician. 2000;46:72-73.

11. American Diabetes Association. Screening for type 2 diabetes. Diabetes Care. 2004;27:11-14.

12. Enright PL, McBurnie MA, Bittner V, et al. The six-minute walk test: a quick measure of functional status in elderly adults. Chest. 2003;123:387-398.

13. Ingle L, Reddy P, Clark AL, Cleland JF. Diabetes lowers six-minute walk test performance in heart failure. $J$ Am Coll Cardiol. 2006; 47:1909-1910.
14. Ben Saad H, Prefaut C, Tabka Z, et al. 6-minute walk distance in healthy North Africans older than 40 years: influence of parity. Resp Med. 2009;103:74-84.

15. Jenicek M, Cleroux R. Clinical epidemiology: its evolution and role in clinical practice and research. Union Med Can. 1985;114:625-632.

16. Al Snih S, Fisher M, Raji M, Markides K, Ostir G, Goodwin J. Diabetes mellitus and incidence of lower body disability among older Americans. J Gerontol A Biol Sci Med Sci. 2005;60:1152-1156.

17. Ben Saad H, Babba M, Boukamcha R, et al. Submaximal exercise capacity and quality of life in exclusive water-pipe smokers. Rev Mal Respir. 2010;27:489-495.

18. Abdelghani A, Ben Saad H, Ben Hassen I, et al. Evaluation of the deficiency and the submaximal exercise capacity in obstructive sleep apnoea patients. Rev Mal Respir. 2010;27:266-274.

19. Ferris BG. Epidemiology standardization project II: recommended respiratory disease questionnaires for use with adults and children in epidemiological research. Am Rev Respir Dis. 1978;118:7-52.

20. Ben Saad H, Khemiss M, Bougmiza I, et al. Spirometric profile of narghile smokers. Rev Mal Respir. 2011;28:e39-e51.

21. Ben Saad H. The narghile and its effects on health. Part I: the narghile, general description and properties. Rev Pneumol Clin. 2009; 65:369-375

22. Ben Saad H. The narghile and its effects on health. Part II: the effects of the narghile on health. Rev Pneumol Clin. 2010;66:132-144.

23. Voorrips LE, Ravelli AC, Dongelmans PC, Deurenberg P, Van Staveren WA. A physical activity questionnaire for the elderly. Med Sci Sports Exerc. 1991;23:974-979.

24. World Health Organization. Obesity: Preventing and Managing the Global Epidemic. Geneva: WHO; 1997:3-5.

25. Assmann G, Cullen P, Schulte H. Simple scoring scheme for calculating the risk of acute coronary events based on the 10-year follow-up of the prospective cardiovascular Münster (PROCAM) study. Circulation. 2002;105:310-315.

26. Okada M, Matsui H, Ito Y, Fujiwara A, Inano K. Low-density lipoprotein cholesterol can be chemically measured: a new superior method. J Lab Clin Med. 1998;132:195-201.

27. American Diabetes Association. Diagnosis and classification of diabetes mellitus. Diabetes Care. 2005;28 Suppl 1:37-42.

28. Sergysels R, Hayot M. Evaluation of exercise-induced dyspnea. Rev Pneumol Clin. 1997;53:278-282.

29. Troosters T, Gosselink R, Decramer M. Six minute walking distance in healthy elderly subjects. Eur Respir J. 1999;14:270-274.

30. Seyoum B, Estacio RO, Berhanu P, Schrier RW. Exercise capacity is a predictor of cardiovascular events in patients with type 2 diabetes mellitus. Diab Vasc Dis Res. 2006;3:197-201.

31. Ziegler O, Filipecki J, Girod I, Guillemin F. Development and validation of a French obesity-specific quality of life questionnaire: quality of life, obesity and dietetics (QOLOD) rating scale. Diabetes Metab. 2005;31:273-283.

32. Guyatt GH, Sullivan MJ, Thompson PJ, et al. The 6-minute walk: a new measure of exercise capacity in patients with chronic heart failure. Can Med Assoc J. 1985;132:919-923.

33. Altunkeser BB, Ozdemir K, Içli A, Celik C, Akyürek C, Gök H. Effects of long-term hormone replacement therapy on QT and corrected QT dispersion during resting and peak exercise electrocardiography in post-menopausal women. Jpn Heart J. 2002;43:1-7.

34. Frette C, Barett-Connor E, Clausen JL. Effect of active and passive smoking on ventilatory function women. Am J Epidemiol. 1996; 143:757-65.

35. Qi L, Rifai N, Hu FB. Interleukin-6 receptor gene, plasma C-reactive protein, and diabetes risk in women. Diabetes. 2009;58: 275-278.

36. Baynes JW. Role of oxidative stress in development of complications in diabetes. Diabetes. 1991;40:405-412.

37. Bastard JP, Maachi M, Lagathu C, et al. Recent advances in the relationship between obesity, inflammation and insulin resistance. Eur Cytokine Netw. 2006;17:4-12. 
38. Kusminski CM, Shetty S, Orci L, Unger RH, Scherer PE. Diabetes and apoptosis: lipotoxicity. Apoptosis. 2009;14:1484-1495.

39. Remels AH, Langen R, Gosker HR, et al. PPARgamma inhibits NFkappaB-dependent transcriptional activation in skeletal muscle. Am J Physiol Endocrinol Metab. 2009;297:174-183.

40. Nojima H, Watanabe H, Yamane K, et al. Effect of aerobic exercise training on oxidative stress in patients with type 2 diabetes mellitus. Metabolism. 2008;57:170-176.

41. Sun Z, Liu L, Liu N, Liu Y. Muscular response and adaptation to diabetes mellitus. Front Biosci. 2008;13:4765-4794.

42. Ozşahin K, Tuğrul A, Mert S, Yüksel M, Tuğrul G. Evaluation of pulmonary alveolo-capillary permeability in type 2 diabetes mellitus: using technetium 99 mTc-DTPA aerosol scintigraphy and carbon monoxide diffusion capacity. J Diabetes Complications. 2006;20:205-209.

43. El Achhab Y, Nejjari C, Chikri M, Lyoussi B. Disease-specific healthrelated quality of life instruments among adults diabetic: a systematic review. Diabetes Res Clin Pract. 2008;80:171-184.

44. Brismar T. Abnormal Na-currents in diabetic rat nerve nodal membrane. Diabet Med. 1993;10 Suppl 2:110-112.

45. Thomas DE, Elliott EJ, Naughton GA. Exercise for type 2 diabetes mellitus. Cochrane Database Syst Rev. 2006;3:CD002968.

46. Baldi JC, Snowling N. Resistance training improves glycaemic control in obese type 2 diabetic men. Int J Sports Med. 2003;24:419-423.

47. Dunstan DW, Puddey IB, Burke V, Stanton KG, Morton AR, Beilin LJ. Effects of a short-term circuit weight training program on glycaemic control in NIDDM. Diabetes Res Clin Pract. 1998;40:53-61.

48. Dunstan DW, Daly RM, Owen N, et al. High-intensity resistance training improves glycemic control in older patients with type 2 diabetes. Diabetes Care. 2002;25:1729-1736.

49. Tessier D, Ménard J, Fülöp T, et al. Effects of aerobic physical exercise in the elderly with type 2 diabetes mellitus. Arch Gerontol Geriatr. 2000;31:121-132.
50. Åstrand PO, Rodahl K, Lacour JR, Duizabo D. Handbook of Exercise Physiology. 3rd ed. Paris: Elsevier Masson; 1994:245.

51. Guyatt GH, Townsend M, Keller J, Singer J, Nogradi S. Measuring functional status in chronic lung disease: conclusions from a random control trial. Respir Med. 1991;85 Suppl B:17-21.

52. Marin P, Anderson B, Krotkiewski M, Björntorp P. Muscle fiber composition and capillary density in women and men with NIDDM. Diabetes Care. 1994;17:382-386.

53. Tchissambou BP, Massamba A, Babela JR, Mouanou JK, Mboussa J, Senga P. The effects of smoking and the degree of nicotine dependence on aerobic capacity in sportsmen. Rev Mal Respir. 2004;21:59-66.

54. Berlin I. Smoking-induced metabolic disorders: a review. Diabetes Metab. 2008;34:304-314.

55. Lama VN, Flaherty KR, Toews GB, et al. Prognostic value of desaturation during a 6-minute walk test in idiopathic interstitial pneumonia. Am J Respir Crit Care Med. 2003;168:1084-1090.

56. Paciocco G, Martinez FJ, Bossone E, PielstickerE, Gillespie B, Rubenfire M. Oxygen desaturation on the 6-MWT and mortality in untreated primary pulmonary hypertension. Eur Respir J. 2001;17:647-652.

57. Hart DA, Reno C. Pregnancy alters gene expression in normal synovium: influence of age and parity. J Rheumatol. 1999;26:1775-1784.

58. The Archidoxes of Magic by Theophrastus Paracelsus, translated by Robert Turner. Facsimile reprint of the 1656 edition with introduction by Stephen Skinner, Ibis Publishing, 2004.

59. Simoneau J, Kelley D. Altered glycolytic and oxidative capacities of skeletal muscle contribute to insulin resistance in NIDDM. $J$ Appl Physiol. 1997;83:166-171.

60. Mercier J. Peripheral muscles and metabolic diseases [French]. Rev Mal Respir. 2001;18(Suppl 2):S22-S24. 


\section{Appendix}

\section{Supplementary data \\ Results}

Noninclusion criteria were found in 23 subjects: diabetes insulin-requiring $(n=15)$ or evolving less than 5 years $(n=4)$; nondiabetic subjects $(n=3)$; and type 1 diabetics $(n=1)$.

\section{NIDDM PG: clinical, anthropometric and metabolic characteristics}

The median (first-third quartiles) of NIDDM evolution was 9 (7-12) years, and $93 \%$ of patients were treated by oral antidiabetic medication. The means \pm SD of cigarette and narghile use were $20 \pm 13$ PY and $29 \pm 41 \mathrm{NY}$, respectively. The mean \pm SD of arterial hypertension evolution was $8 \pm 6$ years. All patients with a history of dyslipidemia, thyroid dysfunction, or diabetic retinopathy were treated. History of chronic respiratory diseases included tuberculosis $(\mathrm{n}=5)$, asthma and/or atopy $(\mathrm{n}=4)$, and obstructive sleep apnea $(\mathrm{n}=1)$. History of chronic cardiovascular diseases included MI $(\mathrm{n}=3)$, arrhythmia $(\mathrm{n}=2)$, angina pectoris $(n=1)$, and arteritis of the lower extremities $(n=1)$. History of surgery included abdominopelvic $(n=22)$, thoracic $(\mathrm{n}=2)$, and neurological $(\mathrm{n}=1)$ surgery. Fifty percent and $20 \%$ of patients had low and high physical activity scores, respectively.

\section{Comparison of NIDDM PG versus CG data}

Analysis of the total-sample data revealed the following points.

Compared to CG1, the PG had significantly higher quantities of used cigarettes and narghile; had a significantly higher percentage of cigarette and narghile users; had a significantly higher physical activity score, weight and BMI; had a significantly lower percentage of sedentary subjects or subjects with low SL, and was significantly younger. The 6MWD means (m, \%) of PG with cigarette use $\leq 2 \mathrm{PY}(\mathrm{n}=62,547 \pm 86 \mathrm{~m}$, $95 \% \pm 12 \%)$ or free from dyslipidemia $(\mathrm{n}=33,567 \pm 75 \mathrm{~m}$, $93 \% \pm 11 \%)$ were significantly $(P<0.05)$ lower than those of CG1 ( $\mathrm{n}=174,636 \pm 112 \mathrm{~m}, 100 \% \pm 9 \%)$. 6MWD multiple regression analysis on CG1 shows that some variables were influencing factors only for the NIDDM PG, not the healthy CG1 (ie, obesity, SEL, cigarette use, and oxy-sat ${ }_{\text {rest }}$. This means that those factors were especially important for the NIDDM PG.

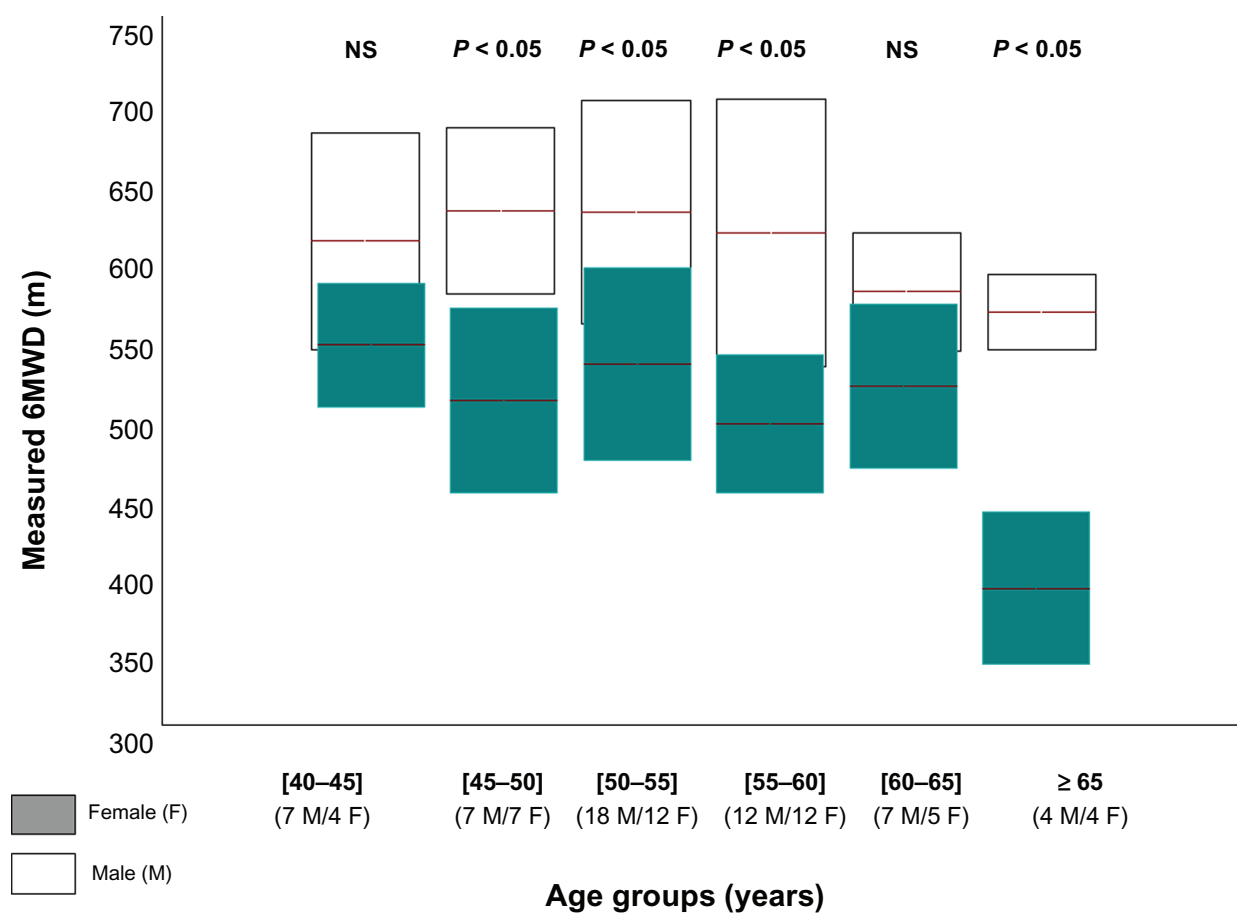

Figure Al The measured 6-minute walk distance (6MWD) of subgroups of non-insulin-dependent-diabetes mellitus males and females, according to age-group. Notes: Data are shown as box-and-whisker plots illustrating the mean \pm standard deviation; $P$, comparison male versus female (paired $t$-test). Abbreviation: NS, not significant. 
Table A I Calculation of absolute cardiovascular disease risk ${ }^{32}$

\begin{tabular}{ll}
\hline & Score \\
\hline Age $\geq 50$ years for males & $+\mathrm{I}$ \\
Age $\geq 60$ years for females & \\
Family history of premature coronary heart disease: & $+\mathrm{I}$ \\
- Myocardial infarction or sudden death $<55$ years with & \\
$\quad$ the father or a relative of first degree of male gender & \\
- Myocardial infarction or sudden death $<65$ years with & \\
$\quad$ the mother or a relative of first degree of female gender & \\
Current smoking or stopped less than 3 years & $+I$ \\
Treated or untreated permanent arterial hypertension & +1 \\
Presence of left ventricular hypertrophy & +1 \\
Treated or untreated non-insulin-dependent diabetes mellitus & $+I$ \\
High-density lipoprotein cholesterol $\leq 1.0 \mathrm{mmol} / \mathrm{L}$ & $+\mathrm{I}$ \\
High-density lipoprotein cholesterol $\geq 1.5 \mathrm{mmol} / \mathrm{L}$ & $-\mathrm{I}$ \\
\hline
\end{tabular}

Compared to CG2, the PG had a significantly higher quantities of used cigarettes and narghile; had a significantly higher percentage of cigarette and narghile users; had a significantly higher physical activity score; had a significantly lower BMI and had a significantly lower percentage of sedentary or obese subjects or subjects having low-SE. Compared to CG2, the PG was significantly taller.

Compared to CG3, the PG had significantly higher quantities of used cigarettes and narghile; had significantly higher weight; had significantly higher percentage of subjects with surgery history; had a significantly lower BMI and had significantly lower percentages of obese patients or patients with chronic respiratory disease. Compared to CG3, the PG was significantly younger.

\section{Discussion}

\section{Study design (recruitment method, inclusion and noninclusion criteria, sample sizes, questionnaires)}

Our cross-sectional study was economical, easy to apply, required less time than a longitudinal one, and provided more useful information. ${ }^{1}$ In the present study, 6MWD values of NIDDM patients were compared with local 6MWD predicted norms, ${ }^{2}$ and with measured 6MWD in three CGs.

As in any study on volunteers, there was possible bias in selection. ${ }^{4}$ However, we limited this bias by the use of a medical questionnaire. ${ }^{4}$

Patients with NIDDM status for less than 5 years weren't included. It has been shown that NIDDM affects lung function only in the long term. ${ }^{5}$ Patients aged under 40 were not included for two reasons: the average age of North African NIDDM patients is around 40 years, ${ }^{6}$ and the 6 MWD local norms were established in adults aged 40 and over. ${ }^{2}$ To avoid
Table A2 Univariate analysis between 6-minute walk distance and the non-insulin-dependent diabetes mellitus patients' group data

\begin{tabular}{|c|c|c|c|}
\hline & $\begin{array}{l}\text { Females } \\
(n=45)\end{array}$ & $\begin{array}{l}\text { Males } \\
(n=55)\end{array}$ & $\begin{array}{l}\text { Total sample } \\
(n=100)\end{array}$ \\
\hline \multicolumn{4}{|c|}{ Smoking status, medical, surgical, and obstetric history } \\
\hline \multicolumn{4}{|c|}{ Cigarette use } \\
\hline Yes & Not done & $595 \pm 59$ & $597 \pm 59$ \\
\hline No & & $637 \pm 75^{*}$ & $547 \pm 86^{*}$ \\
\hline \multicolumn{4}{|c|}{ Narghile use } \\
\hline Yes & Not done & $608 \pm 69$ & $616 \pm 54$ \\
\hline No & & $616 \pm 54$ & $562 \pm 81$ \\
\hline \multicolumn{4}{|c|}{ Chronic respiratory diseases } \\
\hline Yes & $562 \pm 31$ & $588 \pm 46$ & $580 \pm 42$ \\
\hline No & $510 \pm 64$ & $612 \pm 69$ & $564 \pm 84$ \\
\hline \multicolumn{4}{|c|}{ Arterial hypertension } \\
\hline Yes & $521 \pm 42$ & $587 \pm 53$ & $55 I \pm 58$ \\
\hline No & $507 \pm 76$ & $619 \pm 71$ & $574 \pm 91$ \\
\hline \multicolumn{4}{|c|}{ Dyslipidemia } \\
\hline Yes & $514 \pm 69$ & $607 \pm 86$ & $554 \pm 88$ \\
\hline No & $513 \pm 63$ & $609 \pm 65$ & $568 \pm 80$ \\
\hline \multicolumn{4}{|c|}{ Cardiovascular diseases } \\
\hline Yes & $47 I \pm 96$ & $571 \pm 91$ & $528 \pm 100$ \\
\hline No & $516 \pm 61$ & $612 \pm 65$ & $569 \pm 79$ \\
\hline \multicolumn{4}{|c|}{ Dysthyroid } \\
\hline Yes & $537 \pm 15$ & Not done & $537 \pm 15$ \\
\hline No & $511 \pm 66$ & & $567 \pm 82$ \\
\hline \multicolumn{4}{|c|}{ Diabetic retinopathy } \\
\hline Yes & $461 \pm 101$ & $577 \pm 47$ & $534 \pm 88$ \\
\hline No & $577 \pm 60$ & $612 \pm 68$ & $569 \pm 80$ \\
\hline \multicolumn{4}{|c|}{ Surgical history } \\
\hline Yes & $497 \pm 69$ & $595 \pm 69$ & $528 \pm 82$ \\
\hline No & $523 \pm 52$ & $611 \pm 67$ & $578 \pm 25^{*}$ \\
\hline \multicolumn{4}{|l|}{ Parity } \\
\hline Low & $528 \pm 52$ & & \\
\hline High & $467 \pm 74^{*}$ & & \\
\hline \multicolumn{4}{|c|}{ Medication use } \\
\hline \multicolumn{4}{|c|}{ Beta-blocker use } \\
\hline Yes & $491 \pm 66$ & $593 \pm 43$ & $532 \pm 76$ \\
\hline No & $517 \pm 63$ & $610 \pm 69$ & $570 \pm 81$ \\
\hline \multicolumn{4}{|c|}{ Diuretic use } \\
\hline Yes & $551 \pm 43$ & Not done & $57 \mid \pm 54$ \\
\hline No & $511 \pm 64$ & & $566 \pm 82$ \\
\hline
\end{tabular}

Socioeconomic, schooling, and physical activity levels

Socioeconomic level

Low

High

$497+66$

$590 \pm 50$

$520 \pm 74$

Schooling level

Low

$539 \pm 52 *$

$613 \pm 70$

$592 \pm 73^{*}$

High

$494 \pm 65$

$601 \pm 50$

$537 \pm 80$

Physical activity level

Sedentary

$532 \pm 56$ *

$612 \pm 73$

$583 \pm 77^{*}$

Active

$502 \pm 62$

$616 \pm 71$

$543 \pm 69$

Metabolic characteristics

Obesity

\begin{tabular}{llll} 
Yes & $511 \pm 57$ & $584 \pm 47$ & $537 \pm 64$ \\
No & $518 \pm 78$ & $620 \pm 72$ & $592 \pm 86^{*}$ \\
\hline
\end{tabular}

(Continued) 
Table A2 (Continued)

\begin{tabular}{|c|c|c|c|}
\hline & $\begin{array}{l}\text { Females } \\
(n=45)\end{array}$ & $\begin{array}{l}\text { Males } \\
(n=55)\end{array}$ & $\begin{array}{l}\text { Total sample } \\
(n=100)\end{array}$ \\
\hline \multicolumn{4}{|l|}{ Uncontrolled diabetes } \\
\hline Yes & $504 \pm 74$ & $606 \pm 64$ & $562 \pm 85$ \\
\hline No & $515 \pm 47$ & $613 \pm 73$ & $57 I \pm 75$ \\
\hline \multicolumn{4}{|l|}{ Measured dyslipidemia } \\
\hline Yes & $511 \pm 58$ & $610 \pm 76$ & $565 \pm 84$ \\
\hline No & $519 \pm 75$ & $608 \pm 47$ & $567 \pm 75$ \\
\hline \multicolumn{4}{|c|}{ Anthropometric data and parity } \\
\hline Age (years) & $-0.54 * *$ & $-0.25 * *$ & $-0,34^{* *}$ \\
\hline Weight (kg) & 0.09 & -0.10 & 0.03 \\
\hline Height $(m)$ & 0.24 & 0.20 & $0.57^{* *}$ \\
\hline Body mass & 0.02 & -0.22 & $-0.3 \mid * *$ \\
\hline index $\left(\mathrm{kg} / \mathrm{m}^{2}\right)$ & & & \\
\hline Parity (numerical) & $-0.44^{* *}$ & & \\
\hline \multicolumn{4}{|l|}{ Metabolic data } \\
\hline $\begin{array}{l}\text { Fasting glycemia } \\
\text { (mmol/L) }\end{array}$ & 0.05 & -0.03 & 0.01 \\
\hline $\begin{array}{l}\text { Glycated hemoglobin } \\
\text { (\%) }\end{array}$ & -0.16 & 0.06 & 0.01 \\
\hline Triglycerides (mmol/L) & -0.04 & 0.09 & 0.13 \\
\hline $\begin{array}{l}\text { Total cholesterol } \\
(\mathrm{mmol} / \mathrm{L})\end{array}$ & 0.01 & 0.23 & 0.01 \\
\hline $\begin{array}{l}\text { HDL-cholesterol } \\
(\mathrm{mmol} / \mathrm{L})\end{array}$ & -0.08 & 0.16 & 0.03 \\
\hline $\begin{array}{l}\text { LDL-cholesterol } \\
(\mathrm{mmol} / \mathrm{L})\end{array}$ & 0.04 & 0.09 & -0.09 \\
\hline \multicolumn{4}{|c|}{$\begin{array}{l}\text { Physical activity and absolute cardiovascular disease risk } \\
\text { (ACVDR) scores }\end{array}$} \\
\hline \multicolumn{4}{|c|}{ Activities } \\
\hline Daily & -0.11 & 0.02 & $-0.36 * *$ \\
\hline Sporting & 0.16 & -0.18 & $0.19 * *$ \\
\hline Leisure & 0.07 & $0.28 * *$ & $0.31^{* *}$ \\
\hline Physical & 0.15 & -0.05 & $0.24 * *$ \\
\hline ACVDR score & 0.04 & $-0.28 * *$ & $0.21^{* *}$ \\
\hline \multicolumn{4}{|l|}{ 6MWT resting data } \\
\hline Dyspnea (VAS) & 0.23 & -0.21 & -0.05 \\
\hline Heart rate (bpm) & $0.29 * *$ & -0.17 & -0.04 \\
\hline $\begin{array}{l}\text { Systolic pressure } \\
(\mathrm{mmHg})\end{array}$ & -0.04 & $-0.30 * *$ & $-0.20 * *$ \\
\hline $\begin{array}{l}\text { Diastolic pressure } \\
(\mathrm{mmHg})\end{array}$ & 0.25 & -0.21 & -0.01 \\
\hline Oxy-sat (\%) & 0.18 & $0.29 * *$ & $0.21^{* *}$ \\
\hline
\end{tabular}

Notes: Data are expressed in means \pm standard deviation; $* P$ (probability $t$-test) $<0.05$; **P (coefficient of correlation) $<0.05$.

Abbreviations: HDL, high-density lipoprotein; LDL, low-density lipoprotein; 6MWT, 6-minute walk test; VAS, visual analog scale; bpm, beats per minute; oxy-sat, oxyhemoglobin saturation.

potential confounding effects, we did not include patients with type 1 diabetes or with type 2 diabetes requiring insulin. As a precaution, 6MWT contraindications, which increase the risk of arrhythmia or collapse, were applied as noninclusion criteria. ${ }^{?}$

The sample size of the PG $(n=100)$ is less important than other studies related to the 6MWT of NIDDM patients, over the age of 68 years $(n=282)^{8}$ or with heart failure $(n=256) .{ }^{9}$
Table A3 Frequency in the present study and in the literature of risk factors and certain comorbidities in non-insulin-dependent diabetes mellitus ${ }^{33-36}$

\begin{tabular}{lll}
\hline & $\begin{array}{l}\text { Frequency of the } \\
\text { phenomenon in } \\
\text { the present study }\end{array}$ & $\begin{array}{l}\text { Prevalence of } \\
\text { the phenomenon } \\
\text { in the literature }\end{array}$ \\
\hline $\begin{array}{l}\text { Smoking (cigarettes, } \\
\text { narghile) }\end{array}$ & 46 & 64 \\
$\begin{array}{l}\text { Sedentary status } \\
\text { Low socioeconomic level }\end{array}$ & 50 & 38 \\
Obesity & 36 & 38 \\
Dyslipidemia & 48 & 52 \\
Arterial hypertension & 37 & 50 \\
Cardiovascular diseases & 7 & 49 \\
Chronic respiratory & 10 & 25 \\
diseases & & 4.7 \\
Diabetic retinopathy & 8 & 29 \\
\hline
\end{tabular}

However, our sample size was calculated using a prediction equation. ${ }^{10}$

The physical activity questionnaire ${ }^{11}$ - interesting physical activities performed during the last 12 months - is reproducible.

\section{Precautions taken during 6MWT}

NIDDM patients were told to continue their usual oral antidiabetic medication, since its use doesn't affect exercise tolerance. ${ }^{12}$ Sources of variability caused by the procedure of the 6MWT itself were controlled as much as possible. Indeed, the 6MWT was performed as recommended in the open air in a corridor of $40 \mathrm{~m}$ length. A shorter corridor reduces $6 \mathrm{MWD}$, since patients take longer to return. ${ }^{2,7}$ To minimize intraday variability and the effects of biological rhythms, the 6MWT were made in the morning ( $8 \mathrm{am}$ to $10 \mathrm{am}$ ). ${ }^{7}$ Similarly, we avoided encouragement known to increase 6MWD. ${ }^{7}$

\section{Effect of parity}

Effect of parity on the 6MWD can be explained by several hypotheses. First, hormonal alterations during pregnancy could generate aerobic system incapacity. ${ }^{13}$ As the 6MWT solicits the aerobic system, ${ }^{7}$ repeated gestations may accentuate or prolong this incapacity. Biochemical modifications were also suggested, since increased oxidative stress has been found during pregnancy. ${ }^{14}$ With repeated gestations, the repeated oxidative stress could have negative effects on muscle function, explaining in part the 6MWD decline with high parity. Lastly, impaired respiratory muscle function is associated with high parity, ${ }^{15}$ which may have influenced the ventilatory response in our subjects during exercise. 


\section{Other factors explaining the submaximal aerobic capacity decline}

\section{Inflammation and apoptosis}

It is now well known that NIDDM patients have systemic, ${ }^{16}$ adipose tissue ${ }^{17}$ and muscle ${ }^{18}$ inflammation. This inflammation degenerates muscle in several ways; for example by the activation of the ubiquitin-proteasome system ${ }^{19}$ and stimulation of apoptosis. ${ }^{20}$

\section{Oxidative stress}

The imbalance between pro-oxidants and antioxidants in favor of the former is an inseparable partner of inflammation. It is a factor in cell destruction, including muscle, but also induces changes in deoxyribonucleic acid. ${ }^{21}$ In patients with NIDDM, oxidative stress, a consequence of a state of chronic hyperglycemia, ${ }^{16}$ causes both a reduction in insulin secretion and decreases its action, adding to the state of insulin resistance. We believe that as in patients with chronic respiratory disease, ${ }^{22}$ this oxidative stress increased significantly with overall exercise, resulting in muscle dysfunction. ${ }^{22}$

\section{Abnormalities of glucose and lipid metabolism}

NIDDM results in morphological and functional abnormalities, including alterations in the hormonal system, enzymes, transport systems, use of energy substrates, and modulation of blood flow. ${ }^{23}$ Indeed, it has been shown that the alteration in blood flow causes a reduction in the supply of glucose, which contributes to the decrease in total glucose uptake. ${ }^{24}$ Abnormalities of glucose metabolism may also reflect alterations in the insulin receptor, such as a decrease in number or capacity for phosphorylation ${ }^{25}$ and decreased translocation of glucose transporter insulin. ${ }^{26}$ Phosphorylation of glucose-stimulated insulin is decreased as well as glycogen synthesis due to a defect in glucose uptake and reduced glycogen synthase activity. ${ }^{27}$ Thus, muscle insulin-resistant patients are characterized by a decrease in oxidative enzyme activity, whereas the ability of anaerobic resynthesis of adenosine triphosphate is increased. ${ }^{28}$ Similarly, there is a decrease in oxidative enzyme activity in the profits of glycolytic enzymes. ${ }^{28}$ Thus, disturbances of carbohydrate metabolism can be summarized in a decrease in total glucose uptake, storage, and oxidation, and alterations in the insulin receptor. ${ }^{29}$ NIDDM patients also have an alteration of lipid oxidation. ${ }^{28}$ The rate of free fatty acids is increased in diabetics, but their availability and use by the muscle depends on capillarization and transport within the muscle cell, both of which are altered..$^{23,29}$ For example, the activity of carnitine palmitoyl transferase is decreased in metabolic diseases and is negatively correlated with visceral adiposity. ${ }^{23}$ Several other enzymatic mechanisms that allow the use of free fatty acids are also deficient as malate dehydrogenase and citrate synthase. ${ }^{30}$

\section{Abnormalities of the microcirculation}

Abnormalities of the microcirculation are represented by the decrease in local blood flow, the ability to recruit, and capillary density. ${ }^{23}$ So there is less availability of energy substances. $^{23}$

\section{Abnormalities of muscle-fiber type}

Changes in muscle-fiber types are characterized by a decrease in oxidative type I fibers and increased type II fibers, less insulin sensitivity, and low endurance. ${ }^{31}$ This results in a "deconditioning" of the peripheral muscles.

\section{References}

1. Berry G. Longitudinal observations, their usefulness and limitations with special reference to the forced expiratory volume. Bull Physiopathol Respir (Nancy). 1974;10:643-656.

2. Ben Saad H, Prefaut C, Tabka Z, et al. 6-minute walk distance in healthy North Africans older than 40 years: influence of parity. Resp Med. 2009;103:74-84.

3. Ganguli M, Lytle ME, Reynolds MD, Dodge HH. Random versus volunteer selection for community-based study. J Gerontol A Biol Sci Med Sci. 1998;53:39-46.

4. Ferris BG. Epidemiology standardization project II: recommended respiratory disease questionnaires for use with adults and children in epidemiological research. Am Rev Respir Dis. 1978;118:7-52.

5. Barrett-Connor E, Frette C. NIDDM, impaired glucose tolerance, and pulmonary function in older adults. The Rancho Bernardo Study. Diabetes Care. 1996;19:1441-1444.

6. Bouguerra R. The global diabetes pandemic: the Tunisian experience. Eur J Clin Nutr. 2007;61:160-165.

7. American Thoracic Society. ATS statement: guidelines for the sixminute walk test. Am J Respir Crit Care Med. 2002;166:111-117.

8. Enright PL, McBurnie MA, Bittner V, et al. The six-minute walk test: a quick measure of functional status in elderly adults. Chest. 2003;123:387-398.

9. Ingle L, Reddy P, Clark AL, Cleland JF. Diabetes lowers six-minute walk test performance in heart failure. $J$ Am Coll Cardiol. 2006; 47:1909-1910.

10. Jenicek M, Cleroux R. Clinical epidemiology: its evolution and role in clinical practice and research. Union Med Can. 1985;114:625-632.

11. Voorrips LE, Ravelli AC, Dongelmans PC, Deurenberg P, Van Staveren WA. A physical activity questionnaire for the elderly. Med Sci Sports Exerc. 1991;23:974-979.

12. Fang ZY, Sharman J, Prins JB, Marwick TH. Determinants of exercise capacity in patients with type 2 diabetes. Diabetes Care. 2005;28:1643-1648.

13. Bessinger RC, McMurray RG, Hackney AC. Substrate utilization and hormonal responses to moderate intensity exercise during pregnancy and after delivery. Am J Obstet Gynecol. 2002;186:757-764.

14. Jauniaux E, Poston L, Burton GJ. Placental-related diseases of pregnancy: involvement of oxidative stress and implications in human evolution. Hum Reprod Update. 2006;12:747-755. 
15. Ben Saad H, Tfifha M, Harabi I, et al. Factors influencing ventilatory variables of Tunisian women aged 45 years and more. Rev Mal Respir. 2006;23:324-238.

16. Qi L, Rifai N, Hu FB. Interleukin-6 receptor gene, plasma C-reactive protein, and diabetes risk in women. Diabetes. 2009;58:275-278.

17. Bastard JP, Maachi M, Lagathu C, et al. Recent advances in the relationship between obesity, inflammation and insulin resistance. Eur Cytokine Netw. 2006;17:4-12.

18. Remels AH, Langen R, Gosker HR, et al. PPARgamma inhibits NFkappaB-dependent transcriptional activation in skeletal muscle. Am J Physiol Endocrinol Metab. 2009;297:174-183.

19. Llovera M, García-Martínez C, Agell N, López-Soriano FJ, Argilés JM. TNF can directly induce the expression of ubiquitin-dependent proteolytic system in rat soleus muscles. Biochem Biophys Res Commun. 1997;13:238-241.

20. Kusminski CM, Shetty S, Orci L, Unger RH, Scherer PE. Diabetes and apoptosis: lipotoxicity. Apoptosis. 2009;14:1484-1495.

21. Dröge W. Free radicals in the physiological control of cell function. Physiol Rev. 2002;82:47-95.

22. Barreiro E, Gea J, Corominas JM, Hussain SN. Nitric oxide synthases and protein oxidation in the quadriceps femoris of patients with chronic obstructive pulmonary disease. Am J Respir Cell Mol Biol. 2003; 29:771-778

23. Mercier J. Peripheral muscles and metabolic diseases. Rev Mal Respir. 2001;18(Suppl 2):22-24.

24. Zierath JR, Handberg A, Tally M, Wallberg-Henriksson H. C-peptide stimulates glucose transport in isolated human skeletal muscle independent of insulin receptor and tyrosine kinase activation. Diabetologia. 1996;39:306-313.

25. Goodyear LJ, Giorgino F, Sherman LA, Carey RJ, Smith RJ, Dohm GL. Insulin receptor phosphorylation, insulin substrate 1 phosphorylation and phosphatidylinositol 3-kinase are decreased in intact skeletal muscle strips from obese subjects. J Clin Invest. 1995;95:2195-2204.
26. Perez MA, Raynaud E, Mercier J. Insulin resistance and associated metabolic abnormalities in muscle: effects of exercise. Obesity. 2001; 2:47-59.

27. Felberg JP, Haesler E, Jéquier E. Metabolic origin of insulin resistance in obesity with and without type 2 (non-insulin-dependent) diabetes mellitus. Diabetologia. 1993;36:1221-1229.

28. Simoneau J, Kelley D. Altered glycolytic and oxidative capacities of skeletal muscle contribute to insulin resistance in NIDDM. $J \mathrm{Appl}$ Physiol. 1997;83:166-171.

29. Moulias S. Myopathies of the elderly. Rev Rhum. 2004;71:510-514.

30. Bouchard C, Tremblay A, Després JP, et al. The response to long-term overfeeding in identical twins. N Engl J Med. 1990;322:1477-1482.

31. Marin P, Anderson B, Krotkiewski M, Björntorp P. Muscle fiber composition and capillary density in women and men with NIDDM. Diabetes Care. 1994;17:382-386.

32. Assmann G, Cullen P, Schulte H. Simple scoring scheme for calculating the risk of acute coronary events based on the 10-year follow-up of the prospective cardiovascular Münster (PROCAM) study. Circulation. 2002;105:310-315.

33. Gharbi M, Belhani A, Ben Aleya A, et al. Epidemiology of diabetes in Tunisia. Tunis Med. 1995;73:235-239.

34. López Suárez A, Elvira González J, Beltrán Robles M, et al. Prevalence of obesity, diabetes, hypertension, hypercholesterolemia and metabolic syndrome in over 50-year-olds in Sanlúcar de Barrameda, Spain. Rev Esp Cardiol. 2008;61:1150-1158.

35. Touré NO, Dia Kane Y, Diatta A, et al. Tuberculosis and diabetes. Rev Mal Respir. 2007;24:869-875.

36. Ghannem H, Hadj Fredj A. Eating habits and cardiovascular risk factors. Epidemiologic study of the Tunisian Sahel [French]. Presse Med. 1999;28:1005-1008.

\section{Publish your work in this journal}

Diabetes, Metabolic Syndrome and Obesity: Targets and Therapy is an international, peer-reviewed open-access journal committed to the rapid publication of the latest laboratory and clinical findings in the fields of diabetes, metabolic syndrome and obesity research. Original research, review, case reports, hypothesis formation, expert opinion and commentaries are all considered for publication. The manuscript management system is completely online and includes a very quick and fair peer-review system, which is all easy to use. Visit http://www.dovepress.com/testimonials.php to read real quotes from published authors. 